\title{
DOCUMENTACIÓN PREVIA EN LAS INTERVENCIONES DE PATRIMONIO EDIFICADO. ANÁLISIS DE CASO: IGLESIA DE SAN FRANCISCO DE LIMA $[1978-1990]^{(*)}$ \\ PRELIMINARY DOCUMENTATION AT INTERVENTIONS OF BUILT HERITAGE. CASE ANALYSIS: THE CHURCH OF SAN FRANCISCO DE LIMA [1978-1990]
}

\author{
ROSA ALCÁNTARA GÓMEZ ${ }^{(\star)}$ \\ Fecha de recepción: 31 de agosto de 2017 \\ Fecha de aprobación: 21 de noviembre de 2017
}

\begin{abstract}
RESUMEN
En este artículo se analiza un documento del informe final realizado por la Organización de Naciones Unidas para la Educación, Ciencia y Cultura (UNESCO) sobre una intervención realizada en el conjunto de la Iglesia de San Francisco entre 1978 y 1990. No obstante, debido a que este documento reúne más información financiera que técnica, fue necesario recurrir también a otras fuentes, debido a que el propósito principal de este artículo es evidenciar la importancia de la documentación previa en las intervenciones en patrimonio edificado, cuyo análisis permite conocer los antecedentes del inmueble, información crucial para elaborar una futura propuesta de conservación. En primer lugar, se busca dar un panorama general del contexto del país: para ello se explica el contexto político, social y económico que atravesaba el Perú en la época de la intervención del inmueble, así como las condiciones territoriales de Lima y su historia sísmica. Asimismo, se busca entender el concepto de restauración de la época y se detalla la función de los actores protagonistas de este proyecto, la UNESCO y el Instituto Nacional de Cultura (INC), para luego analizar el documento señalado, el Informe Final del Proyecto Nacional PNUD/UNESCO, proyectos PER/77/007 y PER/89/009. Así, se enfatiza la importancia de la documentación previa y posterior para la realización de una intervención en un inmueble mediante el análisis del caso de estudio.
\end{abstract}

\section{PALABRAS CLAVE}

Documentación previa, intervención en patrimonio edificado, Centro Histórico de Lima

\section{ABSTRACT}

The article analyzes a document of the final report produced by the United Nations Educational, Scientific and Cultural Organization (UNESCO) on an intervention carried out in the complex of the Church of San Francisco between 1978 and 1990. Nonetheless, since said document has more financial than technical information, it was necessary to draw on sources, because the purpose of the article is to demonstrate the importance of prior documentation in the interventions of built heritage. Their analysis allows one to know the background of the property, crucial for the elaboration of a future conservation proposal. In the first place, we seek to give a general overview of the country's context: we explain the political, social and economic context in Peru at the time the property was intervened, as well as the territorial conditions of Lima and its seismic history. Also, we seek to understand the concept of restoration had at the time, and detail the role of the main actors in this project, UNESCO and the National Institute of Culture (INC), in order to, then analyze the document, the Final Report of the National Project UNDP/UNESCO, projects PER/77/007 and PER/89/009. Thus, we highlight the importance of previous and subsequent documentation for intervention on a property through the analysis of the case study.

\section{KEYWORDS}

Preliminary documentation, intervention at built heritage, Historical Center of Lima

(*)Este artículo es parte del desarrollo de un trabajo de investigación del curso Metodología de Intervención en el Patrimonio Inmueble, a cargo del MSc. Arq. José Hayakawa Casas, del tercer ciclo de la Maestría en Gestión del Patrimonio Cultural de la Unidad de Posgrado de la Facultad de Ciencias Sociales de la Universidad Nacional Mayor de San Marcos (UNMSM), durante 2016.

$\left(^{* *}\right)$ Bachiller en Artes Plásticas y Visuales, con mención en Conservación y Restauración, por la Escuela Nacional Superior Autónoma de Bellas Artes del Perú. Actualmente cursa estudios de maestría en Gestión del Patrimonio Cultural en la UNMSM. Trabaja en la recuperación del patrimonio desde 2009 en entidades particulares y realiza servicios independientes de restauración para diferentes instituciones. Contacto: rsmalcantara@gmail.com 


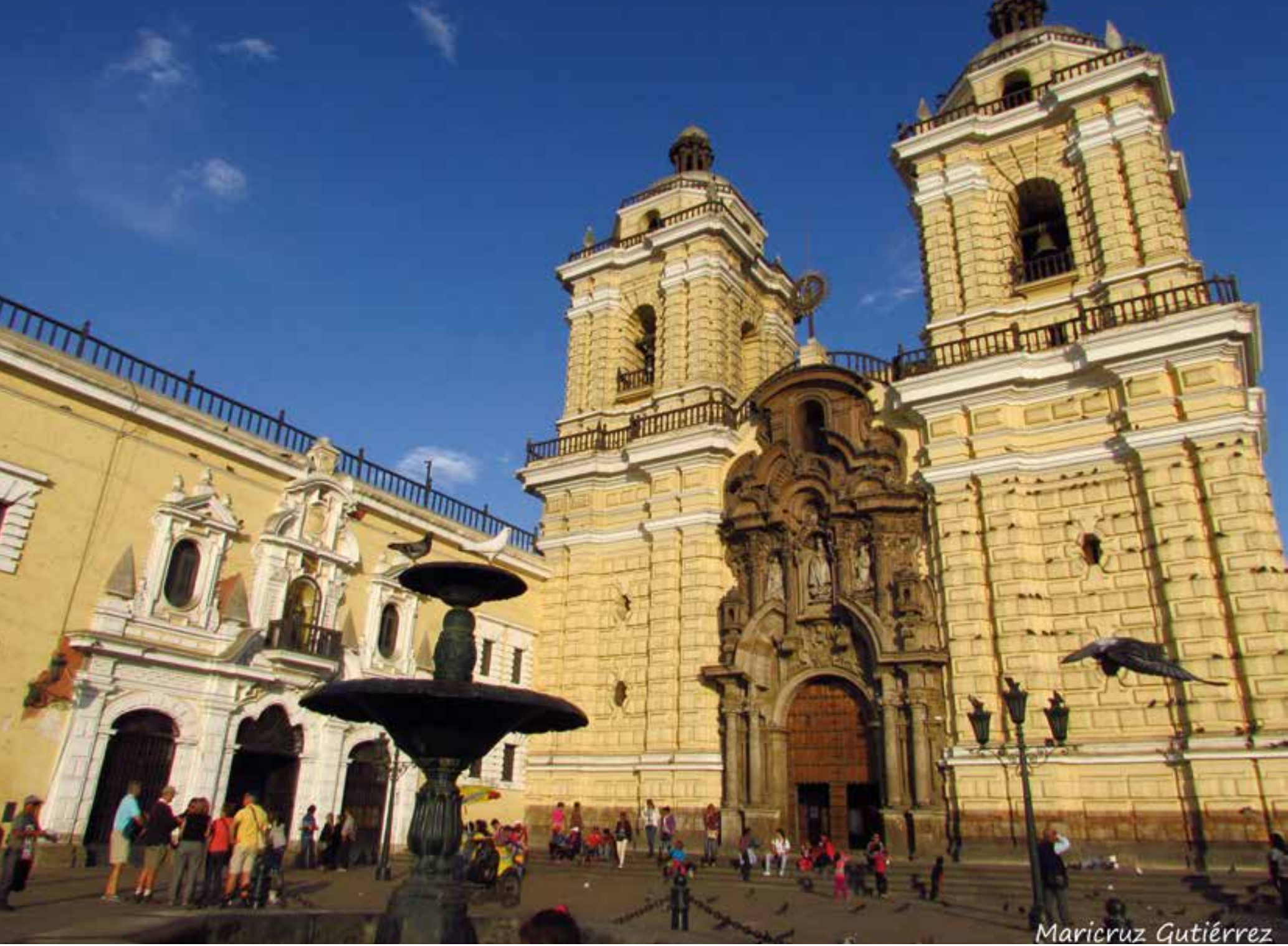

Figura 1. Fachada de la Iglesia de San Francisco de Lima, 2014. Por M. Gutiérrez, recuperado de https://rramuzci.files.wordpress.com/2014/12/ sf.jpg
Para llevar a cabo este estudio de caso resulta necesario conocer el entorno y los acontecimientos ocurridos en aquella época, en cuanto a los aspectos que se relacionan de forma extrínseca (política, cultural, geográfica) e intrínseca (criterios de intervención de patrimonio inmueble). En este último caso se analizará únicamente la primera etapa de intervención, la documentación previa, para así determinar una metodología adecuada de intervención. Se expondrá las posturas de diversos autores al respecto, y se realizará una comparación con la información obtenida durante la intervención realizada por la UNESCO. Para ello se realizó una recopilación bibliográfica de libros, artículos, etc., mediante reiteradas visitas al Archivo del Convento de San Francisco, donde se encontró gran cantidad de datos sobre la intervención. Además, en primera instancia se realizó una entrevista al arquitecto Víctor Pimentel Gurmendi, para obtener un panorama de su participación en proyectos anteriores, lo cual sirvió para enfocar e iniciar el presente artículo.

En décadas anteriores se han realizado innumerables intervenciones en bienes inmuebles en Lima; no obstante, en la mayoría de los casos no se cuenta con registro de ello. Son pocas las ocasiones en que es posible encontrar documentos que relaten detalladamente los estudios que anteceden a la intervención y los procedimientos realizados durante esta. En otros casos, estos contienen únicamente información sobre los gastos, y en otros se trata de textos destinados a la difusión masiva. Este último es el caso de la documentación que se conserva respecto de la intervención realizada en el Convento Iglesia de San Francisco (Figura 1) por la UNESCO: explica a grosso modo los criterios utilizados en la intervención y detalla los estados financieros. Incluye una 

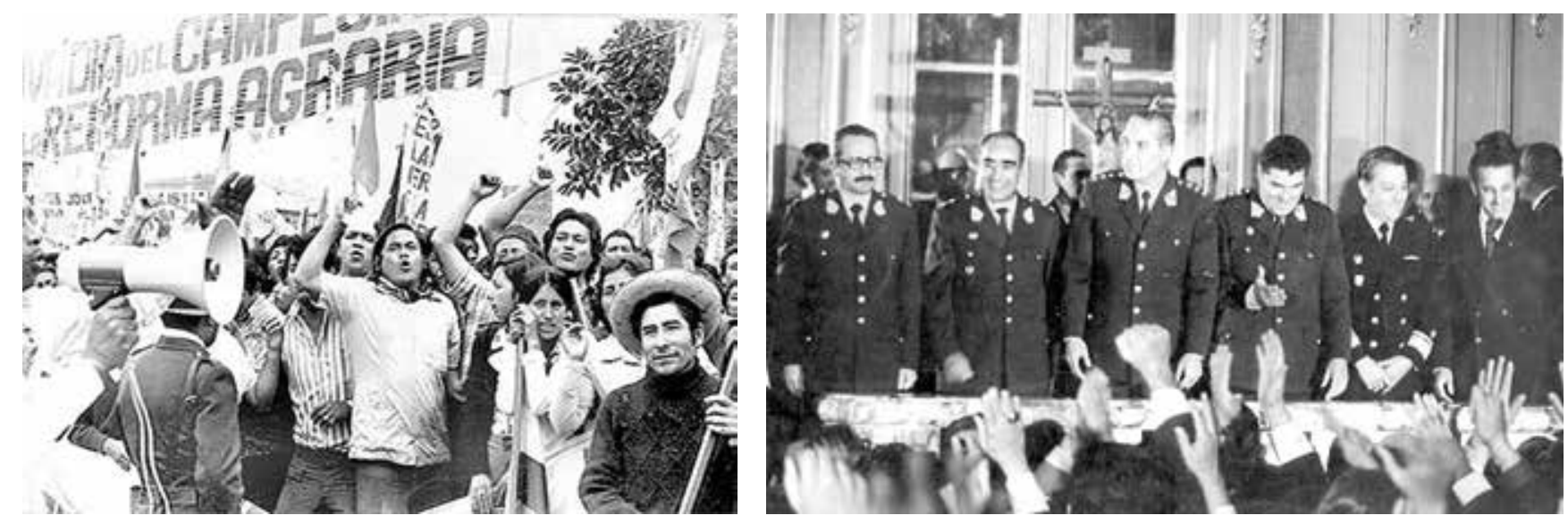

revista de difusión sobre el trabajo realizado, pero, con respecto a la información técnica (los estudios previos, materiales empleados, la ubicación en mapas de las zonas intervenidas, el registro fotográfico de un antes y después), esta no figura dentro del informe. En una primera búsqueda de información en el Archivo del Convento de San Francisco, esta se percibió como dispersa y escasa, pero una segunda visita y búsqueda más profunda permitió encontrar detalles sobre las intervenciones realizadas en el Conjunto Monumental de San Francisco, que contribuyeron a complementar y demostrar, mediante gráficos y mapas, la importancia de los estudios que deben realizarse antes de llevar a cabo una intervención.

El documento que aquí se analiza, el informe final sobre la intervención de la Iglesia de San Francisco, elaborado en 1978 y publicado en 1991, corresponde a un contexto muy distinto al actual, tanto a nivel nacional (social, político) como en cuanto a la forma de concebir las intervenciones en inmuebles patrimoniales.

\section{De la historia política}

Se considera necesario hurgar en la historia para contextualizar al Perú en los años en que se produce la intervención a la Iglesia de San Francisco, tanto en el ámbito político y social como cultural.

Desde los años 60, el gobierno de Juan Velasco Alvarado, instaurado mediante un golpe de Estado, significó grandes cambios que marcarían al país y repercutirían en los siguientes años. La Reforma Agraria; la estatización de las concesiones mineras, y de la industria de la harina y aceite de pescado; la reforma educativa; y, en 1970, la reforma industrial, orientada a alcanzar la independencia económica (Figura 2). Durante dicho periodo se fundaron partidos políticos como la Alianza Popular Revolucionaria Americana (APRA), el Partido Popular Cristiano (PPC), Acción Popular y el Partido Comunista. También tuvo lugar la censura a medios de comunicación, para impedir que brinden información en contra del gobierno. Desde la década del 70 hasta los años 90, el Perú atraviesa una crisis política y económica determinada por una disputa militar por llegar al poder: en 1975, con el llamado "Tacnazo", Francisco Morales Bermúdez continúa con el proceso revolucionario de las Fuerzas Armadas, (Figura 3) y promueve el nuevo plan de reformas en 1977, en el cual se propone una política económica que sigue los lineamientos del Fondo Monetario Internacional y servil al sistema americano. En este se planteaba promover la inversión privada, disminuir los subsidios generando la devaluación de la moneda, la congelación de los sueldos y el alza de costo de vida. Además, se instauró el toque de queda. En 1978"se formula una nueva redacción y en la Constitución de 1979 tuvo en sus novedades más importantes establecer los derechos, las libertades y garantías de los ciudadanos peruanos" (Contreras \& Cueto, 2013, p. 236).
Figura 2. Manifestación por la Reforma Agraria. En "Memorias del Campo Huancavelica y la Reforma Agraria", por J. Ragas, 2016. Uno. Recuperado de https://www.servindi.org/actualidad-opinion/06/02/2018/memorias-del-campo-huancavelica-y-la-reforma-agraria

Figura 3. Gobierno militar encabezado por el presidente Francisco Morales Bermúdez. En "Cuatro Claves para Entender la Sentencia contra Francisco Morales Bermúdez", por C. Blanco, 20 de enero 01 de 2017. Correo. Recuperado de http://idehpucp.pucp.edu.pe/ idehpucp_medios/cuatro-claves-para-entender-la-sentencia-contra-francisco-morales-bermudez/ 

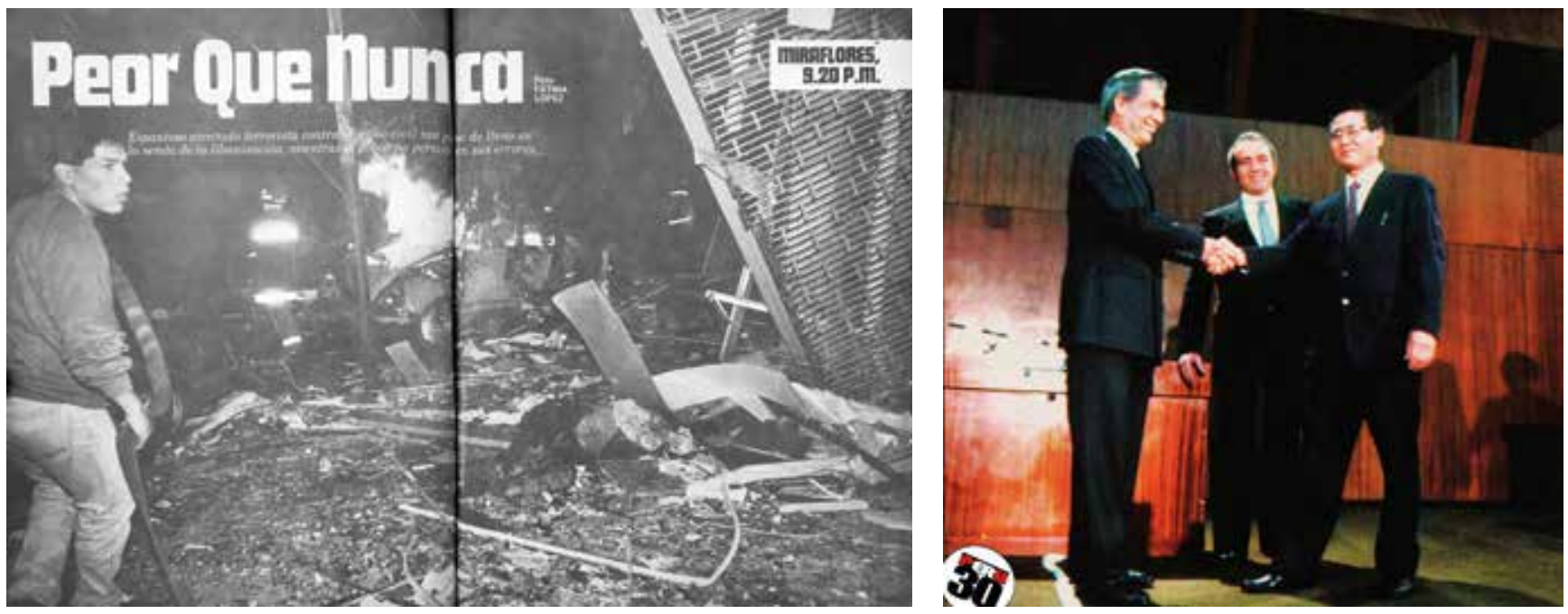

Figura 4. Atentado de Sendero Luminoso en Miraflores, 1992 [fotografía publicada originalmente en la revista Caretas]. Recuperado de https://twitter.com/hurgamemoriape/ status/754369143017705472.

Figura 5. Mario Vargas Llosa y Alberto Fujimori en el debate para las elecciones de 1990. En "Debate presidencial Vargas Llosa-Fujimori-1990". Perú 30. Recuperado de https:// peru30.files.wordpress.com/2010/09/ vargasllosa-fujimori-debate-1990.jpg
Según Contreras y Cueto, pocos años después, en los 80 , se habían suscitado cambios significativos:

Pero el Perú no era el de 1978. Para empezar la población del país había crecido y se había vuelto mucho más citadina... Lima era una urbe de poco más de 4'700,000 habitantes.... En el balance del Gobierno militar se debe contar el retroceso en la productividad agraria, la retracción de la inversión privada, un abultado endeudamiento externo y un exagerado gasto en armamento. (2013, p. 365)

Cuando se inició el segundo gobierno de Belaunde, el gobierno buscaba convivir con las reformas heredadas por el gobierno militar. Entonces surgieron movimientos terroristas en Ayacucho, como Sendero Luminoso, que llevó a cabo diversos atentados contra la población (Figura 4).

Hacia 1985, durante el gobierno de Alan García, se aplicaron políticas económicas que terminaron por generar una profunda crisis, que incluyó desactivaciones que afectaron a la clase media. Se acusó de enriquecimiento ilícito a los funcionarios del Estado, ocasionado por la burocratización y la corrupción administrativa; además, surge la inflación. En los años 90 el país se encontraba en desorden, sobre todo financiero. En las elecciones de 1990 se enfrentaron por el puesto presidencial Alberto Fujimori y Mario Vargas Llosa. Este último fue derrotado, ante el practicismo político de su contrincante (Figura 5). Fujimori inició su mandato llevando a cabo un reordenamiento político fiscal, un shock, para reducir la inflación y estabilizar la moneda. En 1992 dirigió un autogolpe y disolvió el Congreso, tras lo cual convocó a una Asamblea Constituyente para que se le devolviese la legalidad a la democracia: "La justificación del gobierno fue lograr una política eficaz contra el terrorismo y la corrupción política" (Benito, 1997, cap. 12, párr. 4).

Los peruanos mayores de 30 años recordamos los acontecimientos ocurridos en nuestro país a causa del terrorismo, desajustes políticos cuyos efectos aún se perciben. Actualmente la desconfianza ante una posible nueva dictadura y abuso de poder se ha manifestado en las últimas elecciones en 2011 y 2016, ya que existe en la población cierto rezago de temor, aunque con anhelos de cambios y superación.

\section{De la historia sísmica}

Los acontecimientos políticos no fueron el único factor que impactó al Perú durante esos tiempos. Por su ubicación, este se vio afectado por la ocurrencia de desastres naturales. 
El Perú, situado en el Cinturón de Fuego, está casi al borde de dos placas tectónicas: "la principal fuente que genera estos sismos se encuentra en la superficie de la fricción existente entre las placas de Nazca y Sudamericana debido al proceso de convergencia que se desarrolla entre ambas" (Instituto Geofísico del Perú, 2010, p. 8). Enrique Silgado, en su artículo titulado "Historia Sísmica de los Sismos más Notables del Perú", cuenta que el terremoto más destructivo en la historia peruana se produjo en mayo de 1970. Causó alrededor de 70 mil víctimas, entre muertos y desaparecidos, en su mayor parte en el departamento de Áncash. Otro sismo se registró en 1746, el cual afectó numerosas edificaciones y ocasionó un tsunami que impactó en el puerto del Callao, donde se registró la pérdida de un total de 4 mil personas y apenas 200 sobrevivientes. Más adelante, en 1940, otro movimiento sísmico, que alcanzó los 8.2 grados en la escala de Richter, causó 179 muertos y 3,500 heridos. Ocurrieron también terremotos en lugares como Arequipa, en 1948 y 1958: uno de 7.5 grados, cuyos efectos alcanzaron Moquegua, Tacna y Puno; y otro de 7 grados. En ese mismo departamento, se sintieron otros dos movimientos sísmicos, uno en 1979, de 6.9; y el otro en 1988, de 6.2 grados: "El terremoto más reciente en el sur (en los departamentos de Arequipa Moquegua y Tacna) se dio en junio de 2001, con una magnitud de 6.0 grados. Causó importantes daños en un área de 55,500 km², afectando gran parte del suroccidente del Perú" (Silgado, 2007, párr. 5).

En 1974, se produjo el último sismo registrado en Lima, de 8.0 en la escala de Richter, suficiente para causar grandes daños en toda la costa, seguido de innumerables réplicas que profundizaron los perjuicios (Figuras $6,7,8,9,10$ y 11 ) en los distritos de La Molina, Cercado de Lima, El Rímac, Barranco, Chorrillos, San Miguel, Magdalena del Mar y Miraflores, aunque impactó con mayor severidad en el Callao, la Punta y la Perla, donde ocasionó gran deterioro en edificaciones de concreto y pérdidas totales en construcciones de adobe. Los bienes patrimoniales inmuebles, como las casonas e iglesias del Centro de Lima, entre ellos la Iglesia de San Francisco de Asís, no permanecieron intactos ante este acontecimiento.

\section{De la restauración de inmuebles en la Lima: 1978}

En la publicación Restauración en Lima. Pasos y Contrapasos, del MSc. Arquitecto José Hayakawa Casas, se hace referencia a un segundo momento de la restauración de monumentos en Lima, entre 1964 y 1990, periodo que comprende la intervención que aquí se aborda. Hayakawa adjudica a dicha frase las siguientes características:

- La capacitación de la especialización mediante un estudio sistemático y específico de historia, arte, tecnología y arqueología.

- Aproximación método-científica de su perfil profesional, incorporando a su accionar una mayor conciencia histórica de sus intervenciones además de una mayor base ideológica -especialmente la Carta de Venecia- casi inexistente anteriormente. (2010, p. 32)

En cuanto al nivel profesional de los arquitectos restauradores, el autor diferencia dos grupos, con perfiles diferentes:

- Primera generación profesional (perfil más ortodoxo):Víctor Pimentel Gurmendi, Manuel Ganoza, Alberto Barreto, Cossi Salas, Alberto Bueno, Frederic Engel.

- Segunda generación profesional (perfil más heterodoxo): José Correa, Ramiro Salas, Jorge Cosmópolis, José García Bryce, Frederick Cooper, Bertha Estela, Rosa Fung y Humberto Ghersi Barrera.

Así mismo, menciona algunas intervenciones realizadas durante ese periodo:

- El Paraíso, por Frederick Engel (1965-1966)

- Huallamarca, por Arturo Jiménez Borja (1965) 
Figura 6. Derrumbe de muro de vivienda a causa del terremoto de 1974 [fotografía publicada originalmente en la revista Caretas]. En

POF

Figura 7. Daños ocasionados en la cúpula de la Iglesia de San Francisco. En San Francisco de Lima. Rescate de

un Patrimonio (p. 8), por UNESCO, 1 de

Figura 8. Deterioro en una de las columnas de la Iglesia de San Francisco. En San Francisco de Lima. Rescate de unio, 1987. Recuperado de ttp.//whc unesco.org/en/documents/107081

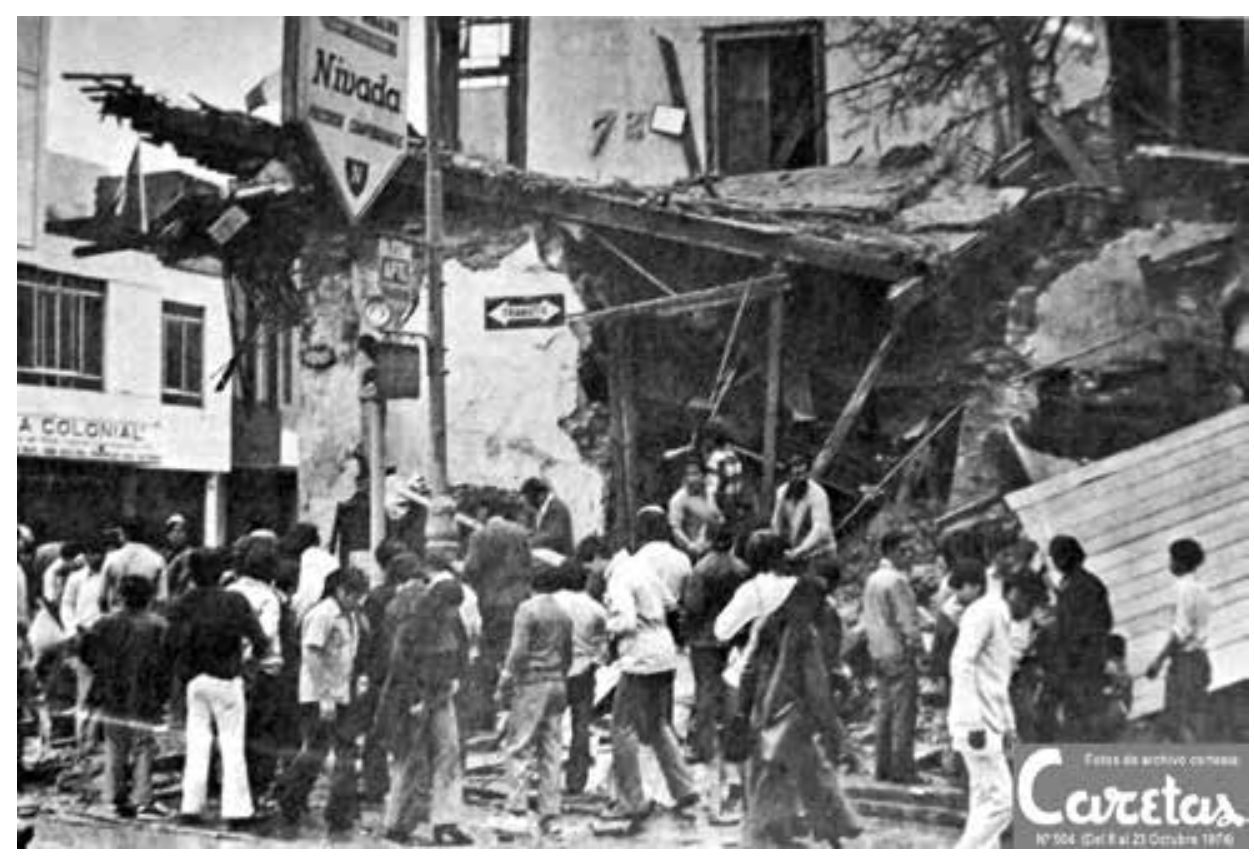

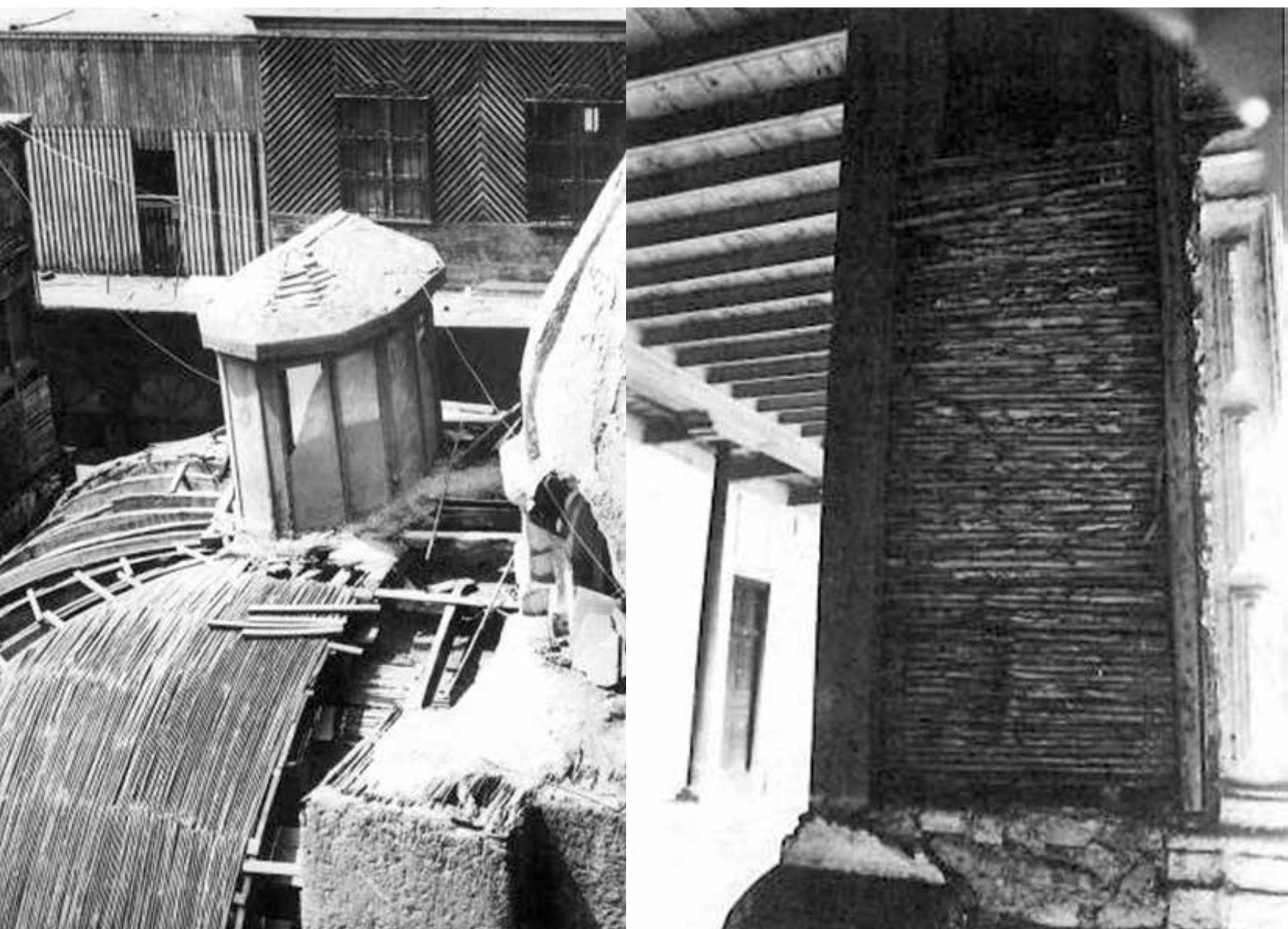



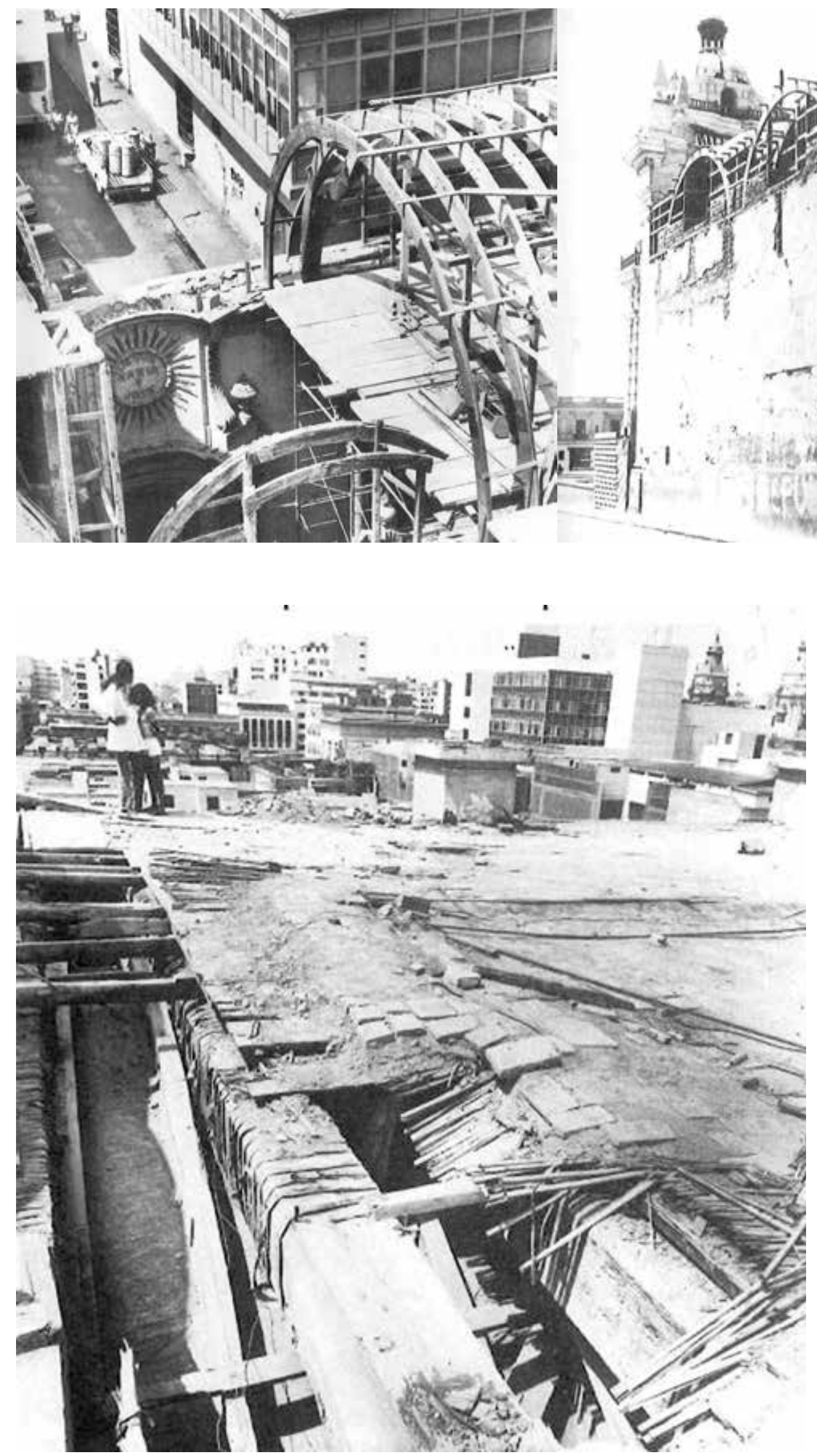

Figura 9. Caída de cubierta en el techo de la Iglesia de San Francisco, que deja a la vista la estructura. En San Francisco de Lima. Rescate de un Patrimonio (p. 27), por UNESCO, 1 de junio, 1987. Recuperado de ttp://whc unesco.org/en/documents/107081

Figura 10. Caída de parte del techo de la Iglesia de San Francisco. En San Francisco de Lima. Rescate de un Patrimonio (p. 30), por UNESCO, 1 de junio, 1987. Recuperado de ttp://whc unesco.org/en/documents/107081.

Figura 11. Rajaduras y desprendimiento en muro de la Iglesia de San Francisco. En San Francisco de Lima. Rescate de un Patrimonio (p. 31), por UNESCO, 1 de junio, 1987. Recuperado de ttp://whc.unesco.org/en/documents/107081 


\author{
- Huaca del Parque Zonal Tupac Amaru, por Cossi Sallas y Casafranca (1969) \\ - Huaca Santa Catalina, por Humberto Ghersi Barrera (1970-1975) \\ - Huaca del Parque de las Leyendas, por Cossi Salas (1972) \\ - Conjunto Monumental de San Francisco, por Víctor Pimentel y Humberto Rodríguez Cami- \\ Iloni (1974-1975) \\ - Casa Osambela, por Víctor Pimentel y José Niño (1981-1984) \\ - Casa Jiménez, por José Correa y José Gálvez (1985) \\ - Quinta Presa, por Bertha Estela y Juan Luis Birimisa (1985) \\ - Casa de ejercicios espirituales de la Orden Franciscana Seglar de Lima, por Víctor Pimentel \\ (1987) (Hayakawa, 2010, p. 32)
}

\section{De los actores institucionales}

Resulta crucial conocer las instituciones relacionadas a los proyectos de recuperación de patrimonio que estuvieron vigentes en 1978 y que intervienen como actores institucionales en el documento aquí analizado, para así poder entender sus posturas y sus objetivos con relación al patrimonio cultural: el INC y la UNESCO.

César Coloma (2001) comenta el origen del INC: este fue primero denominado Dirección de Educación Artística y Extensión Cultural, creada por Ley 9359 (Ley Orgánica de Educación Pública), promulgada el 1 de abril de 1941 por el presidente Manuel Prado. Dicha dirección tuvo como objetivo "organizar y vigilar la enseñanza de las Bellas Artes y difundir la cultura" (p. 14) y estaba compuesto por cinco secciones: Bellas Artes, Museos y Monumentos Nacionales, Editorial y Bibliotecas Nacionales y Populares, Radiodifusión y Cine Educativos, y Patronatos Escolares, junto con la coordinación del Patronato Nacional de Arqueología, el Consejo Nacional de Conservación y Restauración de Monumentos Históricos, el Consejo de Extensión Musical y la Junta Censora de Películas. A través de esta dirección se promovieron exposiciones de artes plásticas, audiciones musicales populares y concursos; además, se fomentó las artes útiles de los aborígenes; se cooperó en la colección y conservación, en los museos, de todos los objetos relativos a la historia y el arte peruanos; y se impulsó los estudios folclóricos y bibliográficos.

Posteriormente, por Decreto Supremo № 48, del 24 de agosto de 1962 (perfeccionado por Decreto Ley 14479, del 17 de junio de 1963), se creó la Comisión Nacional de Cultura y se estableció la Casa de la Cultura del Perú. Esta institución fue sustituida al crearse el INC por Decreto Ley 18799, del 9 de marzo de 1971, como un organismo público descentralizado del sector Educación:

La finalidad del INC es afirmar la identidad nacional mediante la ejecución descentralizada de acciones de preservación, formación y difusión cultural que propicien la participación de la población y convoquen al sector público y privado a colaborar y participar activamente en ello. (Coloma, 2001, p. 14)

Actualmente, el INC ha sido reemplazado por el Ministerio de Cultura, creado el 21 de julio de 2010 mediante Ley № 29565, suscrita por el presidente de la República, Alan García Pérez, como "un organismo del Poder Ejecutivo responsable de todos los aspectos culturales del país y ejerce competencia exclusiva y excluyente, respecto a otros niveles de gestión en todo el territorio nacional" (Ministerio de Cultura del Perú, 2016, s. p.).

El segundo actor importante, que formuló el documento final de intervención del Conjunto Arquitectónico de la Iglesia de San Francisco de Asís en Lima, es la UNESCO, organismo creado en 1945 para responder a la firme idea de las naciones, forjada por dos guerras mundiales en menos de una generación, de que los acuerdos políticos y 
económicos no son suficientes para construir una paz duradera, sino que la paz debe cimentarse en base a la solidaridad moral e intelectual de la humanidad (UNESCO, 2016).

Entre los temas en los que incide la UNESCO está proteger el patrimonio y fomentar la creatividad, en tanto considera al primero un indicador de identidad que favorece a las comunidades en crisis, que a través de la creatividad permite generar la construcción de sociedades del conocimiento dinámicas, innovadoras y prósperas. Ello implica que el componente cultural sea el impulsor de desarrollo, un desarrollo que prioriza al ser humano, sobre la base del respeto mutuo y diálogo. Para ello se consideran tres ejes estratégicos: la defensa de la cultura y el desarrollo a nivel mundial, la colaboración internacional y el fortalecimiento de las industrias creativas (pluralismo cultural).

Entre los tratados que ha producido la UNESCO en pro del patrimonio cultural se encuentran los siguientes:

- 2005: Convención sobre la Protección y la Promoción de la Diversidad de las Expresiones Culturales

- 2003. Convención para la Salvaguardia del Patrimonio Cultural Inmaterial

- 2001: Declaración Universal sobre la Diversidad Cultural

- 2001: Convención de la UNESCO sobre la Protección del Patrimonio Cultural Subacuático

- 1972: Convención para la Protección del Patrimonio Mundial Cultural y Natural

- 1952,1971: Convención sobre la Protección de los Derechos de Autory Derechos Conexos

- 1970: Convención sobre las medidas que deben adoptarse para prohibir e impedir la importación, exportación y la transferencia de propiedad ilícitas de bienes culturales

- 1954: Convención de la Haya para la Protección de Bienes Culturales en caso de Conflicto Armado (UNESCO, 2016)

\section{La documentación previa ante una intervención}

En primer lugar, es necesario tomar en cuenta que este documento, elaborado por la UNESCO, corresponde a una intervención realizada en 1978, año en que se comenzaba, a nivel internacional, a suscitarse la preocupación de establecer los criterios de intervención en monumentos. Anteriormente ya se habían elaborado cartas y tratados donde se hacen hincapié en la relevancia de la documentación previa al realizar una intervención:

Por ejemplo, la Carta de Atenas (1931) favorece la conservación de los monumentos artísticos e históricos. En ella se expresa que es altamente deseable que las instituciones y los grupos calificados realicen un minucioso estudio de los monumentos antes de llevar a cabo cualquier intervención que suponga reintegración o interpretación. Por otro lado, está la Carta de Venecia (1964), donde respecto del mismo tema se indica que los "trabajos de conservación, de restauración y de excavación irán siempre acompañados de la elaboración de una documentación precisa, en forma de informes analíticos y críticos, ilustrados con dibujos y fotografías" (Instituto Nacional de Cultura, 2007, p. 139).

Otro documento en que se menciona la documentación es la Carta de Restauro (1932):

...es una necesidad de documentar la intervención, también en la restauración de monumentos debe ser una condición esencial y taxativa que una documentación precisa acompañe a los trabajos mediante relaciones analíticas recogidas de un diario de la restauración e ilustradas por diseños y fotografías, de modo que todos los elementos determinantes en la estructura y en la forma del monumento, todas las fases de las obras recomposición, de liberación, de complementación, resulten registrados de un modo permanente y seguro (art 11). (Gonzáles, 1999, p. 441) 


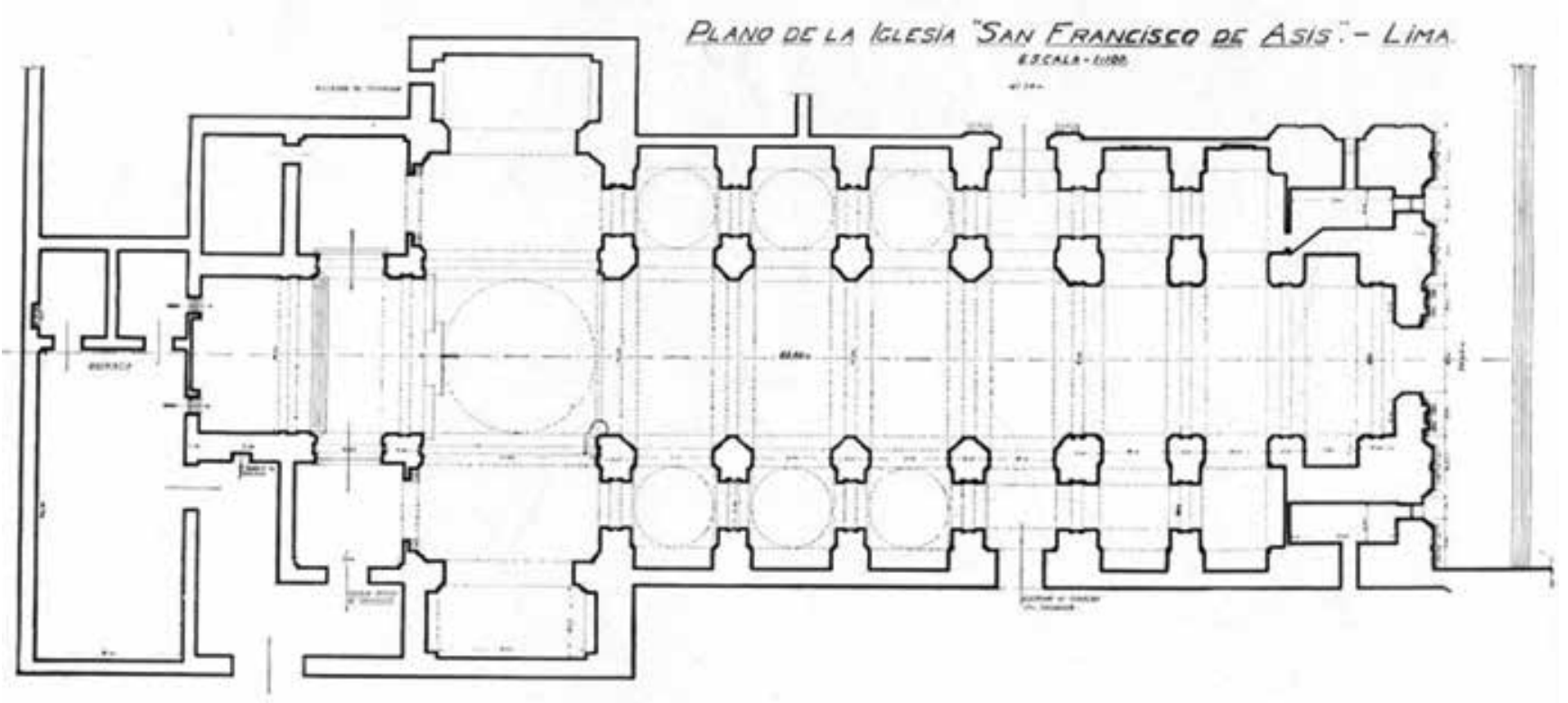

Figura 12. Plano de la planta de la Iglesia de San Francisco. En San Francisco de Lima, Iglesia y Convento; Estudio del Arquitecto Carlos Morales Macchiavello (p. 10), por C. M. Macchiavello, 1941, Lima, Perú.
También cabe mencionar la Convención sobre la Protección del Patrimonio Cultural y Natural (UNESCO, París, 1972), cuyo artículo cuarto afirma sobre la protección internacional del patrimonio cultural lo siguiente:

...reconocer la obligación de identificar, proteger, conservar, rehabilitar y trasmitir a las generaciones futuras el patrimonio cultural y natural situado en su territorio, le incumbe primordialmente. Procurar actuar con ese objeto por su propio esfuerzo y hasta el máximo de los recursos que disponga, y llegado el caso, mediante la asistencia y la cooperación internacionales que se pueda beneficiar, sobre todo en los aspectos financieros, artístico, científico y técnico. (Instituto Nacional de Cultura, 2007, p. 62)

Por lo tanto, puede concluirse que la información sobre la historia de los inmuebles a intervenir no es una recomendación, sino una necesidad, pues se trata data valiosa que permite esclarecer los acontecimientos importantes que marcaron su historia y el deterioro de la materia. Dentro de las actividades previas, se plantea un estudio profundo basado en documentación, como señalan Cristina Gianini y Roberta Roani:

La documentación: documentazione en relación con una operación de restauración de un objeto de interés artístico, la documentación está formada por el conjunto de los resultados de investigaciones históricas, análisis científicos, y pruebas técnicas realizadas en el objeto antes de ser sometido a la intervención. [Especificar la metodología de trabajo y los materiales utilizados en la intervención, el registrar mediante la fotografía como testigo de todos los procesos de la intervención. El autor también recomienda que la información adquirida sea parte de futuras publicaciones científicas, que] quedan como testimonio de una fase de la historia conservativa de una obra y de las tendencias de la época en que se ha realizado la intervención. (2008, p. 72)

Respecto al patrimonio arquitectónico, Marcos Ros (2009) indica tres tipos de fuentes que deben considerarse al recabar información previa sobre un inmueble antes de una intervención.

En primer lugar, menciona los análisis históricos y tipológicos, que consisten en situar a los edificios dentro de su contexto histórico de origen: la fecha de creación, los condicionantes históricos y sociales de la época, los estilos arquitectónicos y los materiales. 

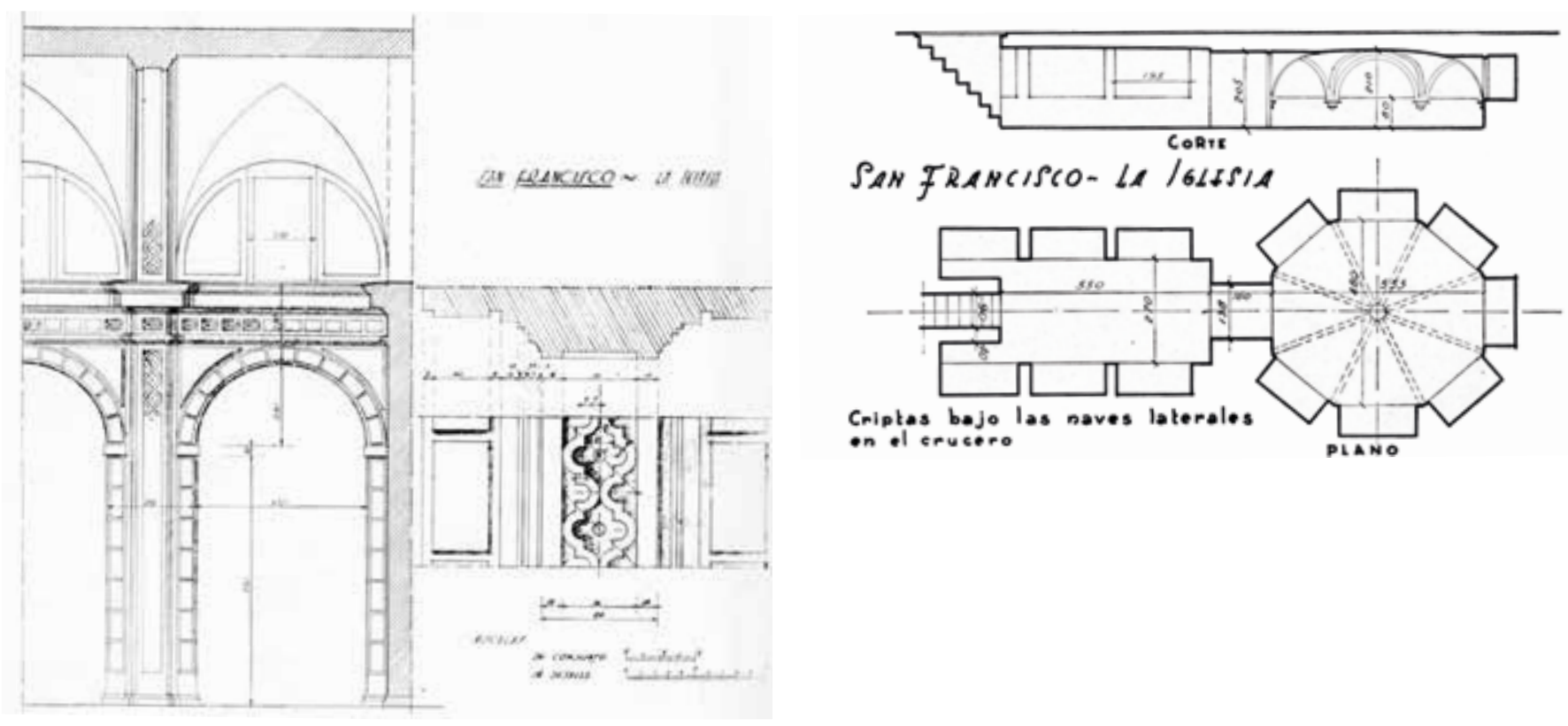

Además, este tipo de estudio implica realizar el análisis formal del edificio, que incluye la descripción de su morfología y elementos principales. Esta fase del análisis abarca de tres aspectos principales: el contexto histórico, la evolución histórica del edificio a lo largo del tiempo, y la descripción de la tipología arquitectónica, con especial atención a los elementos singulares o diferenciadores.

Un modo de recopilar de información es recurrir a fuentes documentales disponibles, orales, escritas y fotográficas: archivos (públicos y privados), bases de datos, documentación registral y/o notarial, colecciones de fotografía y entrevistas personales (testimonios vivos de cómo era el edificio en su época). Se concede especial importancia en este apartado a la documentación fotográfica, que porta información fechada sobre la apariencia de la fachada de diferentes momentos de su historia, lo cual permite determinar las alteraciones que ha sufrido a lo largo del tiempo.

También se lleva a cabo un análisis de carácter constructivo, que consiste en determinar todos los aspectos de la edificación (sistema estructural, materiales, métodos constructivos...). Para ello se recurre a documentación procedente de archivos de colegios de arquitectos y de ayuntamientos sobre el proyecto original, así como a la lectura del propio edificio, entendido como "documento" propiamente dicho (Figuras 12, 13 y 14).

Asimismo, el análisis patológico está orientado a determinar el estado de conservación del edificio y de sus componentes, la existencia o no de lesiones constructivas, y su importancia, grado de avance y localización. También se determina y localiza los elementos ajenos o añadidos innecesariamente. La fuente documental a la que se recurre para esta tercera fase del análisis es básicamente el edificio/documento (Ros, 2009).

José Hayakawa, basándose en las elaboraciones de Joan Feliú Franch, plantea una metodología de cuatro fases de intervención:

$1^{\circ}$ FASE PRE -ESTUDIO INICIAL: se manifiesta las características y el diagnóstico del estado de conservación del objeto a intervenir...

$2^{\circ}$ FASE INVESTIGACIONES Y ESTUDIOS PREVIOS: aquí se busca concretar las conclusiones de la investigación histórica y artística con la información caracterizada y detallada, como también la investigación tecnológica de las patologías...
Figura 13. Plano de levantamiento de la Iglesia de San Francisco. En San Francisco de Lima, Iglesia y Convento; Estudio del Arquitecto Carlos Morales Macchiavello (p. 11), por C. M. Macchiavello, 1941, Lima, Perú.

Figura 14. Plano de las criptas de la Iglesia. En San Francisco de Lima, Iglesia y Convento; Estudio del Arquitecto Carlos Morales Macchiavello (p. 12), por C. M. Macchiavello, 1941, Lima, Perú. 
$3^{\circ}$ FASE DOCUMENTO Y PROYECTO: se plantea la elaboración del proyecto de restauración integrando la metodología de intervención, sus resoluciones y valoración detallada de las fases de intervención...

$4^{\circ}$ FASE EJECUCIÓN MATERIAL Y DIFUSIÓN DEL PROCESO Y RESULTADO: consiste en la realización del proyecto y su posterior integración en la dinámica de la sociedad (2010, pp. 38-39)

Al respecto, Terán menciona lo que los autores anteriores señalan, pero además hace hincapié sobre la información obtenida de los materiales utilizados para la intervención y el uso de otras ciencias:

...conocer los aspectos tecnológicos del inmueble a intervenir, tales como vislumbrar la probable mano de obra que lo realizó, tipo de herramientas, materiales y técnicas constructivas empleados en su erección, así como la procedencia geográfica de dichos materiales... su tipo de alteración, su composición química, la explicación de los mecanismos de un deterioro determinado.... La investigación y adquisición de información respecto a estos asuntos debe ser realizada por especialistas de diferentes disciplinas. (2004, p. 110)

Así, afirma que es necesario conocer los distintos productos que se pretenden emplear en su conservación, ya sea para limpieza, o para eliminación de sales y microorganismos; la compatibilidad de los materiales que se utilizarán en la restauración con los originales, las reacciones químicas que se producen al aplicarse, y si estas son o no de carácter perjudiciales para el bien inmueble, así como el grado de penetración de consolidantes, su tiempo de vida, su toxicidad y peligrosidad.

\section{Caso: Intervención en el conjunto arquitectónico de San Francisco de Lima. Informe Final del Proyecto Nacional PNUD/UNESCO, proyectos PER/77/007 y PER/89/009}

El Informe Final del Proyecto Nacional PNUD/UNESCO, publicado en París en 1991, se inició en 1978 y culminó hacia 1990. Este proyecto fue financiado por los Estados Unidos y significó un gasto total de 675,178 dólares americanos. Tuvo como premisas la restauración del convento de San Francisco de Lima, pedido del Gobierno peruano, así como la recuperación de bienes muebles como ceramios, textiles y pinturas. En este documento se evalúan los resultados obtenidos en los proyectos PER/77/007 Y PER/89/009.

Entre los objetivos de proyecto se encuentran: el apoyo a la restauración del conjunto arquitectónico de San Francisco, al taller de restauración de bienes muebles en San Francisco (restauración de 36 lienzos), al programa de rehabilitación urbana del circuito monumental San Francisco-Rímac, la creación de unidades responsables para el control y de mantenimiento de monumentos y también testimonios urbanos monumentales, y por último, al programa de difusión sobre el estado de emergencia del Convento de San Francisco.

En cuanto a los subproyectos, existen objetivos específicos relacionados a temas arquitectónicos:

\section{Documento del proyecto PER /77/007/A}

Objetivo 1

Programa de apoyo de emergencia al inicio de las obras de arquitectura:

- Proyecto de solución específica para la restauración del muro testero de la Iglesia Mayor y su restauración

- Proyecto de evaluación general del estado estructural del convento y solución de detalle para el claustro mayor 
El resultado de esto fue que, a través de consultorías realizadas entre 1979 y 1981 , se evaluó el estado estructural, y se elaboraron proyectos, adquisición de materiales y equipo necesario para la restauración.

\section{Documento del proyecto PER /77/007/H}

\section{Objetivo 3}

Estudiar los aspectos relacionados con arqueología histórica y su relación con la restauración global del conjunto San Francisco

Para cumplir con este objetivo se contrató dos consultores internacionales, que participaron en seminarios de Arqueología Histórica en 1983 y 1984. En estos se puede observar un proyecto integral de enfoque urbanístico, el interés de capacitar a personal nacional mediante consultores internacionales para que realice los trabajos de restauración, y ganen experiencia para continuar y formar especialistas nacionales que estén a cargo de este tipo de intervenciones. Asimismo, se hizo hincapié en la difusión, con la finalidad de divulgar la gravedad del conjunto arquitectónico de San Francisco para así hacer un llamado a sectores internacionales que contribuyan con la recuperación de este.

El informe detalla el aspecto financiero del proyecto: le da mayor énfasis a los gastos realizados, la importancia de la capacitación a personal nacional y, en cuadros anexos, detalla las personas becadas a los diferentes cursos y seminarios que se dictaron para tal fin.

En una segunda búsqueda exhaustiva de información en los libros del Archivo del Convento de San Francisco, se logró encontrar información técnica que enriquece, explica y grafica las intervenciones realizadas en La Iglesia de San Francisco en aquellos tiempos. Se encontraron innumerables propuestas de intervención de diferentes ambientes de la Iglesia, documentos de todo tipo: memorándums, permisos, informes mensuales, trimestrales, en su mayoría del INC.

\section{Antecedentes del proyecto}

En 1974 los arquitectos Víctor Pimentel Gurmendi y Humberto Rodríguez C. elaboraron un proyecto integral de Conservación del Monumento, Conjunto y Templo de San Francisco a pedido de la misma Orden Franciscana. Para 1975 el Gobierno español financió la restauración de la sacristía, de bóveda; se elaboró el proyecto integral y se adquirió madera para parte de la intervención. En 1977 el Perú, por medio de su Ministerio de Educación, realizó el pedido de restauración del Conjunto de San Francisco a las Naciones Unidas. Ese mismo año, en el mes de diciembre, se firmó el Convenio INC-Orden Franciscana. A inicios de 1978, Amador M'Bow, director la UNESCO, tomó interés en el pedido del Perú y a mediados de ese mismo año se realizó el Convenio INC-PNUD/UNESCO (Proyecto Per77/007).

En 1978 y 79 se realizan las siguientes intervenciones: se restaura el muro testero y el presbiterio, y se apuntala el lado oeste del claustro principal. En 1980 el arquitecto Pastrana de la UNESCO prepara una campaña internacional de salvataje del Conjunto de San Francisco. Ese mismo año se ejecutó la restauración de algunas zonas de la iglesia; también se recibió una donación de parte del Sr. A. Hammer, presidente de la Occidental Petroleum Corporation. Para 1981 el INC solicita la ampliación del proyecto Per77/007 hasta 1984; durante 1981 se continúan los trabajos de restauración en la Iglesia del Milagro y el claustro principal, en los brazos del crucero y la cúpula de la Iglesia Mayor mediante intervenciones de emergencia.

En el informe de 1982 del Proyecto de Restauración del Conjunto Arquitectónico de San Francisco de Lima, informe ubicado en el Archivo de la Iglesia, el arquitecto Jorge Lévano Peña detalla las cifras del financiamiento y su destino. También hace hincapié en los 
avances de los trabajos de restauración, donde da por concluido el muro testero y el presbiterio, los brazos del crucero y la cúpula de la iglesia. La antesacristía mayor se encuentra en proceso, al igual que las intervenciones en el claustro principal y la Iglesia del Milagro.

Menciona el ítem “Jerarquización y Tipos de Intervención", donde se realiza la siguiente clasificación:

- Emergencias: apuntalamientos y/o reforzamientos, consolidación para detener los procesos de deterioro, así lo muestra el plano donde se grafican las áreas de emergencia.

- Restauración: de acuerdo a su estado de conservación en $\mathrm{m}^{2}$ se le dominaría como bueno regular o malo (Lévano, 1982).

\section{Detalles técnicos}

En este ítem interesa mostrar un poco de la metodología, y los materiales propuestos y utilizados durante la intervención de restauración del Conjunto Arquitectónico de San Francisco de Lima. No se profundizará en gastos y financiamiento, debido a que esa información está detallada en el informe final de la UNESCO.

En el Informe $N^{\circ} 1$, del mes de enero, se hace las observaciones sobre las condiciones actuales y posibles recomendaciones. En el caso del muro testero se menciona la propuesta de dar una unidad estructural a todo el conjunto "muro testero-muro laterales" usando una sobrestructura ligera en pórticos de concreto y arriostres de acero, reemplazando la doble tabiquería de ladrillo por otro tipo de cerramiento más ligero; se sugiere la colocación de una malla metálica clavada, y recubierta con mortero de cal y arena.

En el Informe $N^{\circ} 2$, del mes de febrero, se menciona que los lados del muro presentan grietas y rajaduras profundas (INC, 1978).

Entre los documentos encontrados en los libros del Archivo del Convento de San Francisco se encontró un análisis de las condiciones de resistencia y estabilidad de la estructura del arco de crucero de la nave principal, realizado por el ingeniero consultor Ricardo Valencia, donde explica las posibles causas sufridas por esta zona de la arquitectura, como grietas y rajaduras, pero lo más importante es la recomendación metódica de la reparación, la cual extraerá parte del documento transcrito a continuación:

Por eso, las especificaciones técnicas de la reparación deben prescribir: a)la colocación de los tirantes en dos etapas, la primera, con una tracción capaz de equilibrar las presiones agravantes de la inyección; b) la impulsión del mortero de sellado, por etapas, permitiendo que cada tanda de mortero colocado frague, antes de aplicar la dosis siguiente, para que durante el proceso, solo esté actuando en cada instante la presión correspondiente a la reducida porción del relleno requerido; y c) reajuste de los tensores, para inducir en la masa una tensión similar a la cohesión.

Si estas operaciones se ejecutan en forma metódica y controlada especificada, se logrará el restablecimiento virtual de las condiciones previas a los desperfectos una redistribución más homogénea de las tensiones y una mayor capacidad para soportar acciones anormales como las generadas por sismos... (Valencia, 1981, p. 4)

Siguiendo con la búsqueda, se encontraron las especificaciones técnicas para la reparación del arco de crucero de la nave principal mencionada anteriormente, en un documento emitido por el INC. En este se encontraron datos importantes para un estudio previo para una intervención futura, que son los materiales que se decidió utilizar para la reparación, en este caso, del arco del crucero de la nave principal. Se menciona los materiales empleados para

La consolidación, donde los tensores de atirantamiento activo serán de acero de alta resistencia, del orden de $17 \mathrm{mil} \mathrm{kr} / \mathrm{cm}^{2}$ con concreto armado, el sellado de los tirantes y aceros resisten- 


\section{PROPIEDADES FISICAS Y PROMEDIOS DE RESISTENCIA MECANICA DE LAS ESPECIES FORESTALES RECOMENDADAS COMO REEMPLAZO DE ESTRUCTURAS.}

\begin{tabular}{|c|c|c|c|c|c|c|c|c|c|c|c|c|c|c|c|c|c|c|c|c|c|c|c|c|c|c|}
\hline \multirow{3}{*}{$\frac{y}{g}$} & \multirow{3}{*}{ 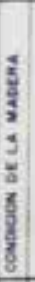 } & \multirow{3}{*}{$\begin{array}{l}\frac{9}{2} \\
\frac{3}{2} \\
\frac{3}{8} \\
\frac{8}{2} \\
\frac{8}{2} \\
\end{array}$} & \multicolumn{3}{|c|}{$\begin{array}{l}\text { PESO } \\
\text { ESPECFOCO }\end{array}$} & \multicolumn{6}{|c|}{ CONTRACCON } & \multicolumn{5}{|c|}{ FLEXON ESTATCA } & \multicolumn{3}{|c|}{$\begin{array}{l}\text { COMPRESION } \\
\text { PARALELA AL GRANO }\end{array}$} & \multirow{3}{*}{ 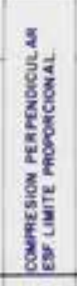 } & \multicolumn{2}{|c|}{$\begin{array}{l}\text { DUREZA } \\
\text { JANKA }\end{array}$} & \multirow{3}{*}{ 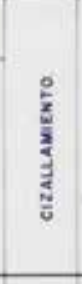 } & \multirow{3}{*}{$\frac{5}{3}$} & \multirow{3}{*}{ 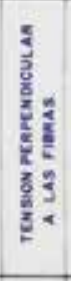 } & \multirow{3}{*}{$\frac{\frac{g}{a}}{\frac{\pi}{2}}$} \\
\hline & & & \multirow{2}{*}{$\begin{array}{l}5 \\
\frac{5}{3} \\
\frac{8}{8} \\
\frac{8}{3} \\
\frac{8}{5}\end{array}$} & \multirow{2}{*}{ 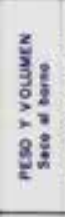 } & \multirow{2}{*}{$\begin{array}{l}\frac{3}{3} \\
38 \\
3 \\
\frac{8}{8} \\
\frac{8}{4}\end{array}$} & \multicolumn{3}{|c|}{ 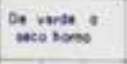 } & \multicolumn{3}{|c|}{$\begin{array}{l}\text { De werse a } \\
\text { seco al ane }\end{array}$} & \multirow{2}{*}{ 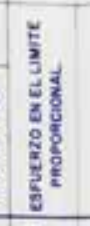 } & \multirow{2}{*}{$\begin{array}{l}\frac{5}{2} \\
\frac{5}{2} \\
3 \\
\mathbf{2} \\
8 \\
8 \\
9 \\
8 \\
8 \\
\end{array}$} & \multirow{2}{*}{ 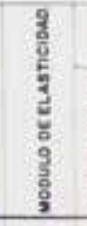 } & \multicolumn{2}{|c|}{ Thenesio } & \multirow{2}{*}{ 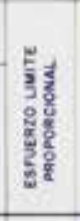 } & \multirow{2}{*}{ 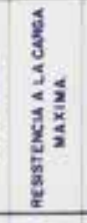 } & \multirow{2}{*}{$\begin{array}{l}9 \\
8 \\
8 \\
5 \\
5 \\
8 \\
8 \\
0 \\
5 \\
5 \\
3\end{array}$} & & \multirow[b]{2}{*}{$\frac{\frac{n}{y}}{\frac{n}{x}}$} & \multirow[b]{2}{*}{$\begin{array}{l}\text { ò } \\
\vdots \\
\vdots\end{array}$} & & & & \\
\hline & & & & & & ईू & 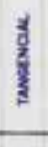 & $\frac{\frac{5}{2}}{\frac{y}{5}}$ & $\frac{\frac{1}{6}}{\frac{1}{x}}$ & $\frac{j}{3}$ & है & & & & 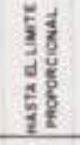 & $\begin{array}{l}\frac{5}{6} \\
\frac{5}{5} \\
\frac{5}{x} \\
\frac{1}{x} \\
\frac{1}{x} \\
\frac{5}{x}\end{array}$ & & & & & & & & & & \\
\hline & & & & & & $\%$ & $*$ & 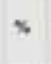 & $\%$ & $\%$ & $\%$ & $\mathrm{xg} / \mathrm{cs}^{2} \times$ & $\mathrm{x}_{0} / \mathrm{cm}^{2}$ & $\begin{array}{l}k_{4} / 20^{2} \\
=1000\end{array}$ & $\operatorname{san}^{\prime}$ & $\mathrm{kg}=\mathrm{m} / \mathrm{m}$, & $\mathrm{Ka} / \mathrm{cm}^{2}$ & $\mathrm{~K} \theta \mathrm{Am} \mathrm{m}^{2}$ & $x_{0}^{\times 100^{2}}$ & $x_{0} / \mathrm{cm}^{2}$ & $\mathrm{Ka} / \mathrm{em}^{2}$ & $\mathrm{~K}_{9} / \mathrm{cos}^{2}$ & $\omega_{9} / \operatorname{lom}^{1}$ & Kagatso & $\sin ^{2}$ & Sow \\
\hline$\xi$ & a & 120 & 043 & 047 & & 23 & 41 & 70 & & & & $9 n$ & 790 & $\begin{array}{l}93979 \\
95800\end{array}$ & $\begin{array}{l}0.95 \\
0.435\end{array}$ & $\begin{array}{l}0 \text { 2ail } \\
0455\end{array}$ & $\begin{array}{l}306 \\
323\end{array}$ & 421 & $\begin{array}{l}10.96 \\
11253\end{array}$ & $\begin{array}{l}775 \\
82.0\end{array}$ & $\begin{array}{l}30 s \\
373\end{array}$ & $\begin{array}{l}396 \\
367\end{array}$ & sis & 48 & $\begin{array}{l}31 \\
31.46\end{array}$ & 141 \\
\hline fit & a & is & $\begin{array}{l}0.52 \\
0.52\end{array}$ & $\begin{array}{l}0.6 \\
0.6\end{array}$ & & 40 & 21 & $\begin{array}{l}123 \\
123\end{array}$ & & & & $\begin{array}{l}3082 \\
630\end{array}$ & $\begin{array}{l}734,3 \\
024\end{array}$ & $\prod_{120}^{111,3}$ & $\begin{array}{l}104 \\
175\end{array}$ & $\begin{array}{l}6.06 \\
11.3\end{array}$ & $\begin{array}{l}212.0 \\
340\end{array}$ & $\begin{array}{l}3192 \\
483.7\end{array}$ & $\begin{array}{l}140.7 \\
140.7\end{array}$ & $\begin{array}{l}623 \\
623\end{array}$ & $\begin{array}{l}4575 \\
6307\end{array}$ & $\begin{array}{l}403 \\
521\end{array}$ & $\begin{array}{l}852 \\
1406\end{array}$ & $\begin{array}{l}52.4 \\
504\end{array}$ & $\begin{array}{l}40.5 \\
38.6\end{array}$ & 234 \\
\hline if & a & 12 & $\begin{array}{l}038 \\
0.39\end{array}$ & & & $\begin{array}{l}40 \\
40\end{array}$ & $\begin{array}{l}80 \\
60\end{array}$ & 37 & & & & $\begin{array}{l}267 \\
9179\end{array}$ & nei & $\begin{array}{l}92.4 \\
95.2\end{array}$ & & 6.96 & 211 & $\begin{array}{l}202 \\
392\end{array}$ & 1028 & 483 & $\begin{array}{l}332 \\
3729\end{array}$ & 2582 & $\begin{array}{l}n 2 \\
n=0\end{array}$ & 57 & be & \\
\hline if & i & & & ose & 0.4 & 39 & 30 & 20 & & & & 28263 & 473.17 & 2226 & 0056 & 0.52 & $\$ 603$ & 21790 & 3653 & $27 \Delta 2$ & 2006 & 20412 & 55.8 & 46.4 & 3.69 & 0.04 \\
\hline 1 & i & $\begin{array}{l}14.46 \\
12\end{array}$ & 044 & OA. & & 48 & 79 & & & & & $\begin{array}{l}302: \\
4047\end{array}$ & $\begin{array}{l}7220 \\
73204\end{array}$ & $\begin{array}{l}18.35 \\
131.40\end{array}$ & $\begin{array}{l}006 \\
007\end{array}$ & $\begin{array}{l}0.02 \\
0.52\end{array}$ & $\begin{array}{l}285.4 \\
2868\end{array}$ & $\begin{array}{l}4: 422 \\
4753\end{array}$ & $\begin{array}{l}151.9 \\
158.4\end{array}$ & $\begin{array}{l}32.8 \\
372\end{array}$ & $\begin{array}{l}40143 \\
4408\end{array}$ & $\begin{array}{l}3648 \\
3065\end{array}$ & $\begin{array}{l}6804 \\
7390\end{array}$ & 4937 & $\begin{array}{l}4460 \\
46.3\end{array}$ & 200 \\
\hline 1 & i & $\begin{array}{l}\text { is. } \\
12.0\end{array}$ & oes & 087 & & 40 & 64 & & & & & $\begin{array}{l}352 \\
4157\end{array}$ & $\begin{array}{l}776 \\
800.3\end{array}$ & $\begin{array}{l}115139 \\
12345\end{array}$ & $\begin{array}{l}0.062 \\
0.079\end{array}$ & $\begin{array}{l}\text { o.se } \\
\text { oets }\end{array}$ & 180.6 & $\begin{array}{l}419 \\
510\end{array}$ & $\begin{array}{l}13527 \\
145.04\end{array}$ & $\begin{array}{l}100393 \\
12102\end{array}$ & $\begin{array}{l}706.6 \\
108.9\end{array}$ & $\begin{array}{l}620 \\
676,1\end{array}$ & $\begin{array}{l}114.7 \\
1272\end{array}$ & 50.67 & $\begin{array}{l}46.3 \\
45.7\end{array}$ & 210 \\
\hline$E$ & i & $\begin{array}{l}901 \\
120\end{array}$ & o: & oen & & 87 & 10.7 & & & & & sin & $\begin{array}{l}14490 \\
11040\end{array}$ & $\begin{array}{l}17994 \\
\text { cosss }\end{array}$ & $\begin{array}{l}\text { los } \\
114\end{array}$ & $\begin{array}{l}0969 \\
0.73\end{array}$ & $\begin{array}{l}2 \pi 43 \\
2 \pi 5\end{array}$ & $\begin{array}{l}6002 \\
6362\end{array}$ & 108.6 & 129.70 & ine? $z$ & 11095 & in : as & so, & 4456 & 363 \\
\hline$\frac{1}{31}$ & a & & 0.48 & & & 3.5 & 92 & & & & & 520 & 913 & 127 & 185 & 69 & & & & & 505 & 990 & & & & \\
\hline 8 & i & 00: & $\begin{array}{l}046 \\
0.46\end{array}$ & $\begin{array}{l}0.52 \\
0.52\end{array}$ & & $\begin{array}{l}\text { is } \\
\text { is }\end{array}$ & 40 & 94 & & & & $\begin{array}{l}388 \\
3 e 6\end{array}$ & $\begin{array}{l}637 \\
942\end{array}$ & $\begin{array}{r}98 \\
106\end{array}$ & $\begin{array}{l}080 \\
163\end{array}$ & $\begin{array}{l}62 \\
60\end{array}$ & $\begin{array}{l}242 \\
958\end{array}$ & $\begin{array}{l}320 \\
491\end{array}$ & $\begin{array}{l}107 \\
106\end{array}$ & 49 & $\begin{array}{l}394 \\
423\end{array}$ & $\begin{array}{l}390 \\
368\end{array}$ & as & 50 & $\begin{array}{l}502 \\
41\end{array}$ & 095 \\
\hline & & & & & & & & & & & & & & & & & & & & & & & & & & \\
\hline
\end{tabular}

tes se hará con mortero sin contracción de fragua, constituido por: 1 bolsa de cemento Porland sin aditamento incorporador de aire, 1 bolsa de Embeco Agr. De 100 libras de peso (Pozzolth); $45 \mathrm{gr}$. De arena cuarzosa limpia, la adherencia requerida para la efectiva acción del atirantamiento se obtendrá con pegamento epóxico del tipo Sika Colma-Dur o similar. (INC, s/f)

Es interesante el detalle de dónde se realizaron las perforaciones, determinando la herramienta a utilizar, la posición a emplear, las profundidades, todo especificado y graficada. Así también se especifica la limpieza de los forados y ductos, al igual que las grietas; estas, en particular, a medida que se van limpiando se fueron cerrando con empastándolo con masilla o yeso puro. En el caso de la inyección en las rajaduras del arco, se rellenaron con mortero de cemento de arena fina o con lechada de cemento, para las grietas muy finas, observando escapes o fugas del material.

\section{Discusión}

Terán (2004) se refiere a la documentación previa y propia del inmueble, pero también a la que señala los materiales que se decidirá utilizar para la intervención; es decir, una vez que el inmueble esté debidamente documentado con información previa que indique cómo llego a su estado actual, así como habiendo entendido el comportamiento de los materiales a utilizar para la intervención y su posible interacción con el material original, por ejemplo, a nivel químico. Al respecto se debe tener presente algunos de los criterios de intervención como el de mínima intervención, compatibilidad de materiales y reversibilidad de materiales, por comentar algunos. Esta información, sobre todo
Figura 15. Cuadro de las propiedades físicas y promedios de resistencia mecánica de las especies forestales recomendadas como reemplazo de estructuras. Instituto Nacional de Cultura, 1978. Proyecto de Restauración de San Francisco de Lima y Museo de Arte Virreinal (Caja № 190, Proy-12) Archivo del Convento de San Francisco, Lima, [Fotografía por R. M. Alcántara, 2017]. 
Figura 16. Gráficos de estabilidad y resistencia del arco del crucero [Fotografía por R. M. Alcántara, 2017].

Reparación de arco de la Nave Central, gráficos de estabilidad, por Instituto Nacional de Cultura, 1980. Proyecto de Restauración de San Francisco de Lima y Museo de Arte Virreinal (Caja № 190, Proy-12). Archivo del Convento de San Francisco, Lima, Perú. la que escapa de los criterios del restaurador, debe ser proporcionada por diferentes especialistas que se dediquen al estudio de material patrimonial, como químicos, físicos o biólogos que desde sus disciplinas aporten información que permite llegar a entender el comportamiento de la materia en diferentes circunstancias. Por ejemplo, en este caso, la Iglesia de San Francisco tiene una estructura de piedra y paredes de adobe, materiales son susceptibles ante fuertes movimientos como sismos de alta escala, que pueden agrietar la estructura de las paredes de adobe, material que además, ante una inundación o exceso de humedad, sufre ablandamiento y puede llegar a colapsar.

En este mismo informe se trata la consolidación de pinturas murales. Según J. Bontcé, una pintura mural es

....un elemento integrante de la arquitectura y no puede ser concebida ni comprendida aislándola del ambiente, constitución lineal, espacios y colores de la construcción de que forma parte... Las técnicas utilizadas tradicionalmente en la pintura mural han sido la pintura al temple, al óleo y al fresco. (1963, p. 130)

Estos elementos, en las situaciones de deterioro que se mencionaron anteriormente, los sismos y la humedad, sufrirían pérdidas por la ruptura del muro y por la humedad, que podría generar abolsados en la pintura, donde esta terminaría desprendiéndose. Ante este riesgo, una posible medida es la consolidación de los estratos para la corrección de los abolsados y la fijación de estos al muro. No obstante, para saber qué tipo de adhesivo utilizar, es necesario saber de qué tipo material se trata, de forma que sea idóneo, compatible con el material original, y que no ocasione daños a lo largo del tiempo. Para resolver esos casos es importante recurrir a las fichas técnicas de los materiales, donde se especifica las características del producto: composición, temperaturas de utilización, toxicidad, riesgos para el hombre, etc. Así lo muestran diferentes instituciones dedicadas a la conservación de patrimonio, como el Grupo Español del International Institute for Conservation of Historic and Artistic Works' ${ }^{1}$, que en su sitio web incluye un ítem de fichas técnicas de diferentes materiales de conservación.

El caso de la intervención en el Conjunto Arquitectónico de la Iglesia de San Francisco no fue ajeno a este procedimiento; como se mencionó anteriormente, fue necesario buscar en los archivos de la iglesia, donde se encontró un cuadro titulado "Propiedades física [sic] y promedios de resistencia mecánica de las especies forestales recomendadas como reemplazo de estructuras" (Figura 15), en el cual se muestran las especies y sus características de acuerdo a su peso contracción, flexión estática, compresión, dureza, etc. De ahí se puede partir para la elección de material idóneo para el remplazo de estructuras.

Así también se encontraron gráficos de estudios de estabilidad y registro de las "lesiones por inyectarse y tirante" para la reparación del arco de la nave central (ver Figuras 16 y 17).

Antonio Gonzales Moreno-Navarro, en su libro La Restauración Objetiva (Método SCCM de Restauración Monumental), cita a Castilla del Pino describiendo a la memoria histórica, como eso que "está en los papeles que llamamos documentos, y está en las piedras que denominamos unas veces fósiles, otras herramientas o útiles, otras esculturas, anfiteatros, calzadas, fustes, capiteles, templos" (1993-1998, p. 17) es ver al inmueble o monumento en su función simbólica, esa que trae recuerdos para las personas, que tienen cierta estimación, y que esta puede llegar a disminuir antes los cambios de una intervención.

Por ello, la necesidad de graficar cada proceso, fases de la intervención, y sobre todo difundirla como una notificación a la comunidad. En este caso de estudio, dicha información, que se encontró en los registro del archivo de la Iglesia de San Francisco,

El Grupo Español del International Institute for Conservation of Historic and Artistic Works (ICC) es una asociación sin fines de lucro, conformada por profesionales de la conservación y restauración de bienes culturales. 


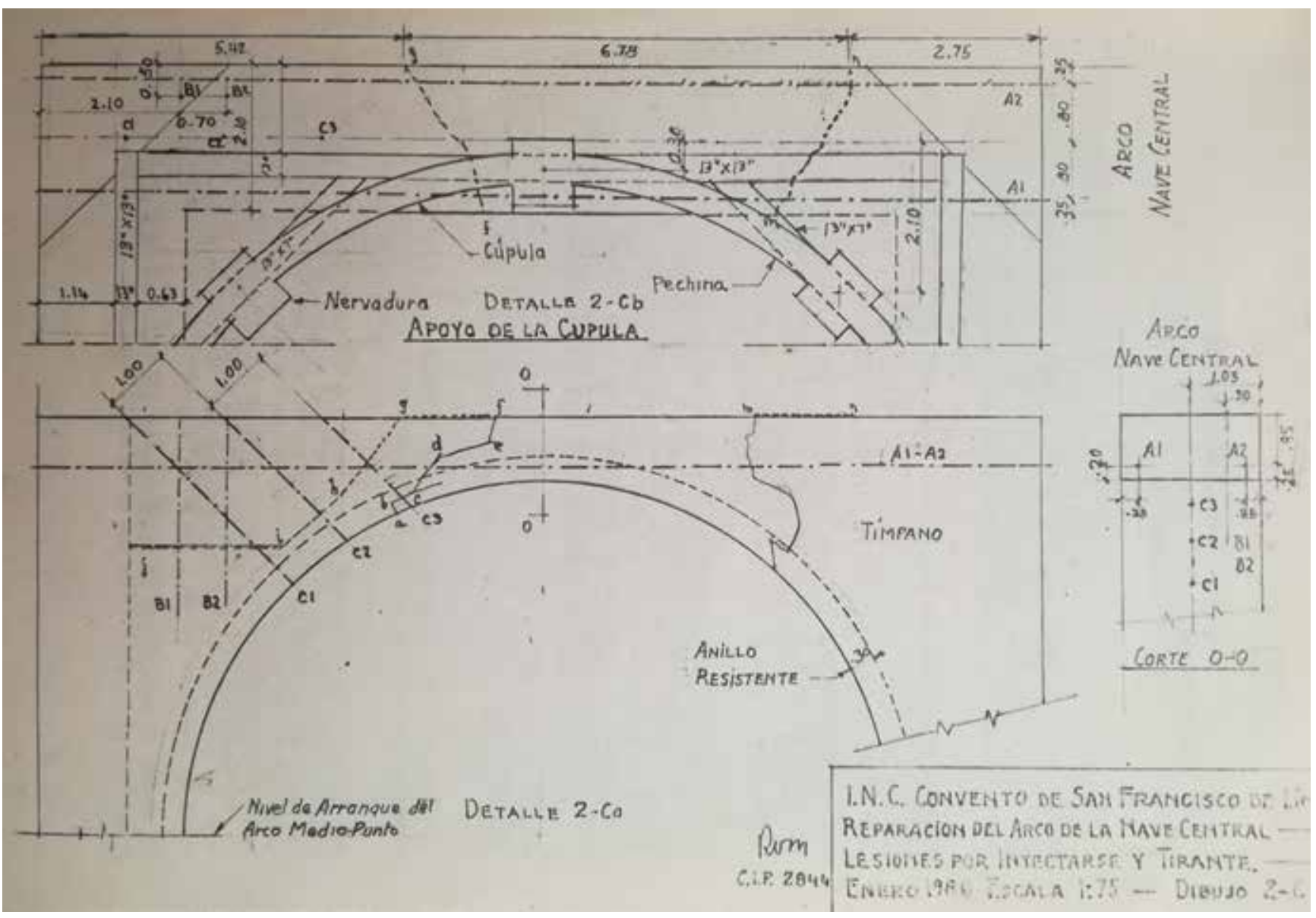

Figura 17. Gráficos de reparación del arco de la nave central, lesiones por inyectarse y tirante. Instituto $\mathrm{Na}$ cional de Cultura, 1978. Proyecto de Restauración de San Francisco de Lima y Museo de Arte Virreinal (Caja № 190, Proy-12). Archivo del Convento de San Francisco, Lima, [Fotografía por R. M. Alcántara, 2017]. resultó muy enriquecedora, pues permitió entender los cambios producidos en la Iglesia durante esa intervención, como lo muestran los planos representados en las Figuras 18, 19, 20, 21 y 22, donde se observan las zonas de excavaciones para el análisis arqueológico, el estado actual del muro testero, las áreas de intervención de emergencia, zonas de trabajo por etapas, y de los agregados en la intervención.

\section{Conclusiones}

La intervención en el Conjunto de San Francisco de Lima, si bien había muchos rezagos políticos, sociales y económicos, pudo iniciarse gracias a la financiación y preocupación de la UNESCO para la recuperación y salvaguarda del patrimonio histórico, que permitió llevar a cabo una campaña de recuperación del patrimonio en general en distintos inmuebles patrimoniales del Centro Histórico de Lima, ejemplo que continuó siendo replicado años más tarde por otras instituciones internacionales, como La Agencia Española de Cooperación Internacional para el Desarrollo (AECID). La cooperación institucional, como fue el caso entre la UNESCO y el INC, fue desarrollada mediante una participación en conjunto, tal cual se pretende en las intervenciones en inmuebles, para lograr la participación y la cooperación de profesionales de distintas disciplinas, que desde sus especialidades puedan contribuir a la conservación del patrimonio.

Con respecto a la documentación de este informe final de la UNESCO, se debe considerar la época de ejecución: si bien es un informe detallado en el aspecto financiero, deja de lado la información técnica de la intervención, y actualmente este tipo de documentación es importante para lograr un buen diagnóstico y proponer una adecuada 

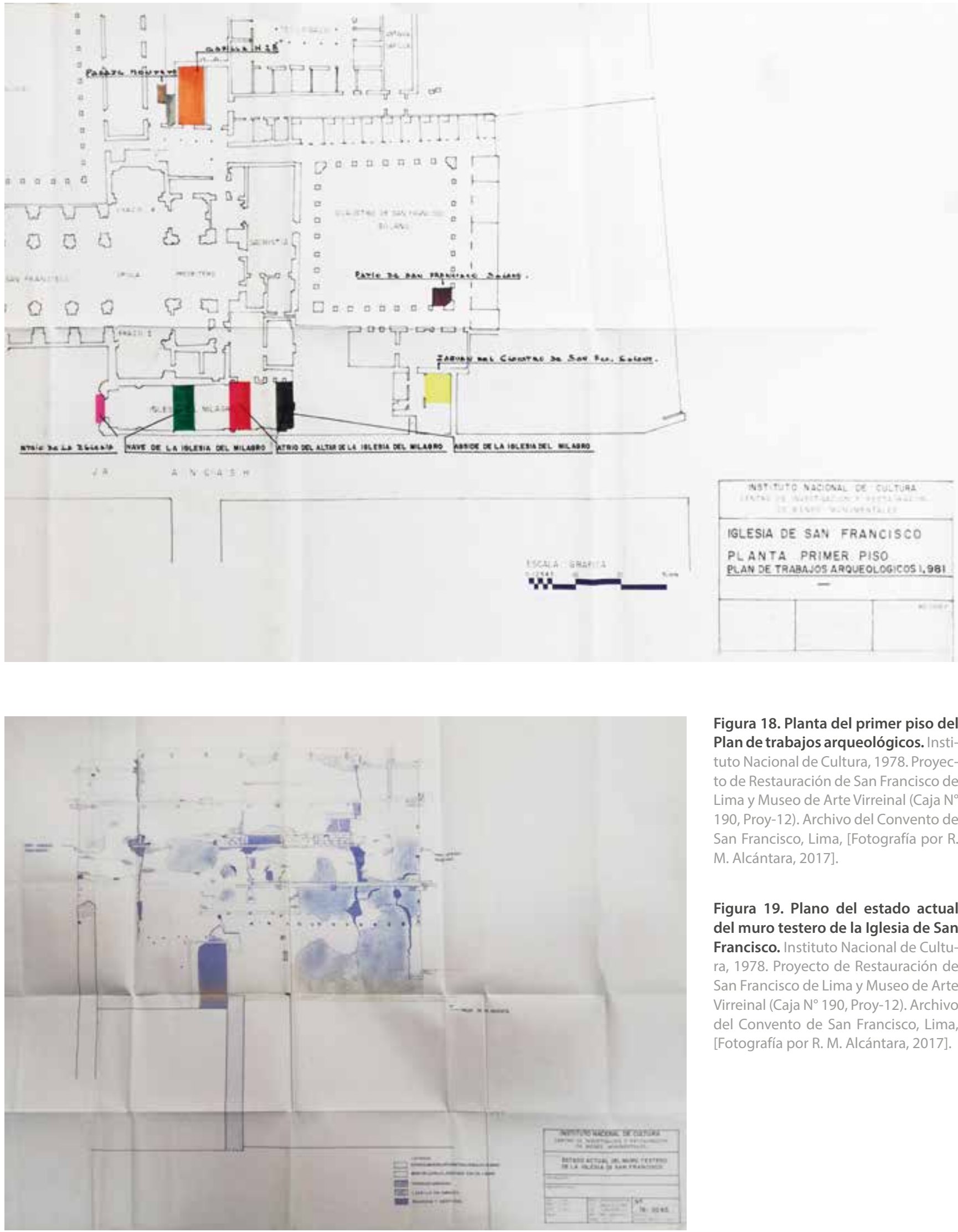

Figura 18. Planta del primer piso del Plan de trabajos arqueológicos. Instituto Nacional de Cultura, 1978. Proyecto de Restauración de San Francisco de Lima y Museo de Arte Virreinal (Caja N 190, Proy-12). Archivo del Convento de San Francisco, Lima, [Fotografía por R. M. Alcántara, 2017].

Figura 19. Plano del estado actual del muro testero de la Iglesia de San Francisco. Instituto Nacional de Cultura, 1978. Proyecto de Restauración de San Francisco de Lima y Museo de Arte Virreinal (Caja № 190, Proy-12). Archivo del Convento de San Francisco, Lima, [Fotografía por R. M. Alcántara, 2017]. 
devenir VOL. 5, N9, ENERO - JUNIO 2018, PP. 29-50 - ESTUDIOS I ISSN 2312-7562 | E-ISSN 2616-4949

UnIVERSIDAd NACIONAL DE INGENIERÍA, LIMA

Figura 20. Plano del estado de áreas de intervención de emergencia del Conjunto de San Francisco. Instituto Nacional de Cultura, 1978. Proyecto de Restauración de San Francisco de Lima y Museo de Arte Virreinal (Caja N ${ }^{\circ} 190$, Proy-12). Archivo del Convento de San Francisco, Lima, [Fotografía por R. M. Alcántara, 2017].

Figura 21. Plano de áreas de trabajo por etapas. Instituto Nacional de Cultura, 1978. Proyecto de Restauración de San Francisco de Lima y Museo de Arte Virreinal (Caja № 190, Proy-12). Archivo del Convento de San Francisco, Lima, [Fotografía por R. M. Alcántara, 2017].
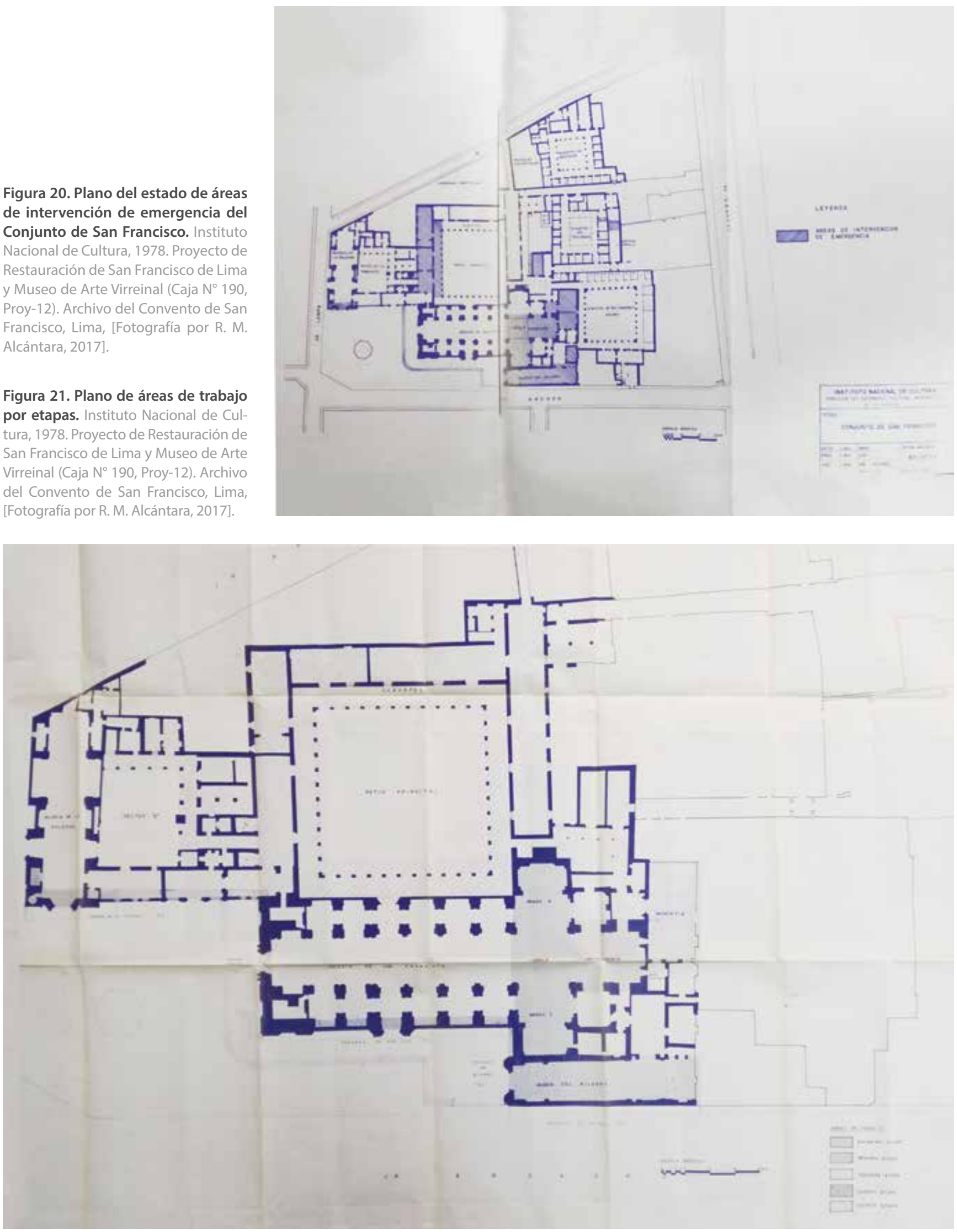


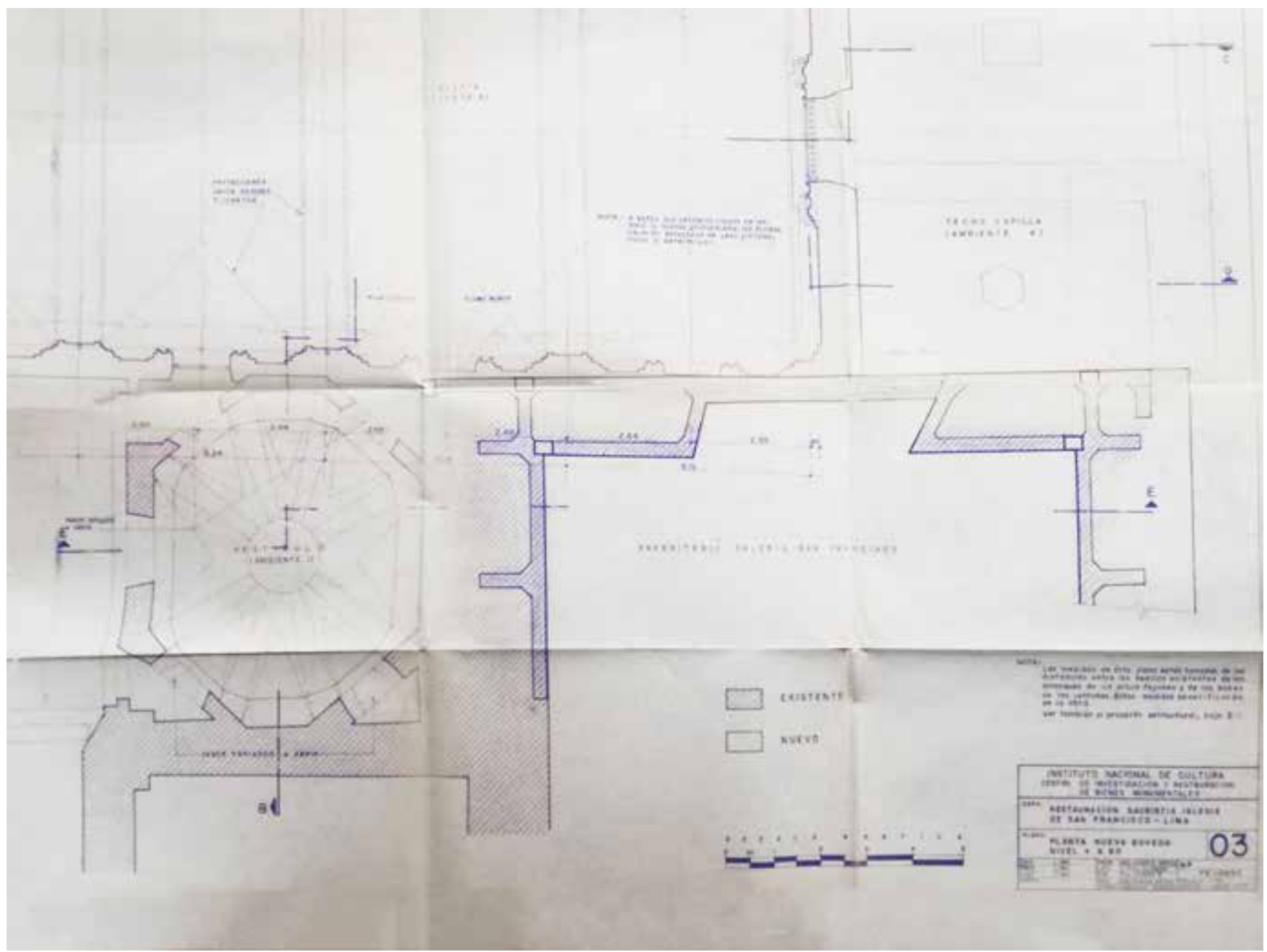

intervención; lamentablemente, para obtenerla hay que rebuscar en archivos especializados, como el del Convento de San Francisco. Hoy en día es necesario que toda intervención sea debidamente documentada y dicha información publicada, que se comparta la investigación previa y posterior, para así generar un documento público que sea parte de la historia del inmueble y no se pierda.

\section{Referencias}

Benito, J. A. (junio, 1997). Apuntes de historia del Perú contemporáneo. Independencia y República: 1780-1997. Recuperado el 26 de octubre de 2016, de http://jabenito.blogspot.com/2015/07/ apuntes-de-historia-del-peru.html

Bontcé, J. (1963). Técnicas y secretos de la pintura. Barcelona, España: Las Ediciones de Arte.

Coloma, C. (26 de marzo, 2001). El Perú y su historia. Recuperado el 19 de diciembre de 2016, de https://sites.google.com/site/elperuysuhistoria/el-instituto-nacional-de-cultura-del-peru

Contreras, C., \& Cueto, M. (2013). Historia del Perú contemporáneo. Desde luchas por la independencia hasta el presente (5ta ed.). Lima, Perú: Instituto de Estudios Peruanos.

Giannini, C., \& Roani, R. (2008). Diccionario de restauración y diagnóstico. Madrid, España: Nerea.

Gonzáles, I. (1999). Conservación de bienes culturales. Teoría, historia, principios y normas. Madrid, España: Cátedra.
Figura 22. Planta de los agregados durante la intervención en la nueva bóveda de la Iglesia de San Francisco de Lima. Instituto Nacional de Cultura, 1978. Proyecto de Restauración de San Francisco de Lima y Museo de Arte Virreinal (Caja N 190, Proy-12). Archivo del Convento de San Francisco, Lima, [Fotografía por R. M. Alcántara, 2017]. 
Hayakawa, J. (2010). Restauración en Lima. Pasos y contrapasos. Lima, Perú: Universidad San Martín de Porres.

Instituto Geofísico del Perú. (setiembre de 2010). Zonificación sísmico-geotécnica para siete distritos de Lima Metropolitana. Lima, Perú: Instituto Nacional de Defensa Civil.

Instituto Nacional de Cultura. (1978). Informe Nº 1 . Lima, Perú: Autor.

Instituto Nacional de Cultura. (1978). Informe N² 2. Lima, Perú: Autor.

Instituto Nacional de Cultura. (noviembre de 2007). Documentos fundamentales para el patrimonio cultural. Textos internacionales para su recuperación, repatriación, conservación, protección y difusión. Lima, Perú: Autor.

Instituto Nacional de Cultura. (s/f). Arco del crucero de la nave principal, especificaciones técnicas. Lima, Perú: Autor.

Lévano, J. (1982). Proyecto de restauración del Conjunto Arquitectónico de San Francisco. Lima, Perú: Instituto Nacional de Cultura / Orden Franciscana.

Macchiavello, C. M. (1941). San Francisco de Lima, iglesia y convento: estudio del arquitecto Carlos Morales Macchiavello. Fotos de Alberto Rozas. Lima, Perú: El Arquitecto Peruano.

Ministerio de Cultura del Perú. (2016). ¿Quiénes Somos? Recuperado el 19 de diciembre de 2016, de http://www.cultura.gob.pe/es/informacioninstitucional/quienessomos

Moreno-Navarro, A. G. (1993-1998). La restauración objetiva (Método SCCM de restauración monumental). Barcelona, España: Diputación de Barcelona.

Organización de las Naciones Unidas para la Educación, la Ciencia y la Cultura. (2016). Sobre la UNESCO. Recuperado el 19 de diciembre de 2016, de http://es.unesco.org/about-us/introducing-unesco

Organización de las Naciones Unidas para la Educación, la Ciencia y la Cultura. (2016). Proteger el patrimonio y fomentar la creatividad. Recuperado el 2016 de diciembre de 2016, de http:// es.unesco.org/themes/proteger-patrimonio-y-fomentar-creatividad

Ros, M. (2009). El Plan de fachadas de casco histórico de Cartagena: Documentación y técnicas. En XX Jornadas de Patrimonio Cultural de Murcia (p. 275). Murcia, España: Tres Fronteras.

Silgado, E. (16 de agosto de 2007). Historia de los sismos en el Perú. La República. Recuperado el 19 de diciembre de 2016, de http://larepublica.pe/16-08-2007/historia-de-los-sismos-enel-peru

Terán, J. (2004). Consideraciones que deben tenerse en cuenta para la restauración arquitectónica. Conserva, 8, 101-122.

Valencia, R. (1981). Informe: Reparación del arco de crucero de la nave central de la Iglesia de San Francisco de Lima. Lima, Perú: Instituto Nacional de Cultura / Orden Franciscana. 